New version: 02/03/2021;

Available online: 16/05/2021; $2^{\text {nd }}$ round notif.: $31 / 03 / 2021$; Published: 16/05/2021;

\title{
Gênero na Educação em Computação no Brasil e o Ingresso de Meninas na Área - uma Revisão Sistemática da Literatura
}

\author{
Title: Gender in Computer Education in Brazil and the Entry of Girls into the Area - A \\ Systematic Review of Literature
}

Suzy Kamylla de Oliveira Menezes

Instituto Federal de Alagoas

Universidade Federal de Alagoas

suzy.kamylla@gmail.com
Mario Diego Ferreira dos Santos

Universidade Federal de Alagoas

mdfs@ic.ufal.br

\begin{abstract}
Resumo
A inserção das mulheres na Computação apresenta desafios que envolvem questões de gênero. Em áreas como a tecnologia ainda é evidente que a atuação feminina é reduzida em comparação ao número de homens. A literatura aponta fatores que atraem e que diminuem o interesse das meninas em relação às disciplinas, cursos e profissões da Computação. Estudos e intervenções que busquem incentivar meninas e jovens para atuar nesta área podem contribuir para aumentar a inserção de mulheres na atuação profissional. O objetivo deste trabalho é analisar fatores relacionados à menor presença feminina em cursos de Computação e quais iniciativas são utilizadas para atrair meninas para essa área. Foi realizada uma Revisão Sistemática de Literatura (RSL) e utilizados os descritores: meninas, alunas, estudantes, ensino médio, ciência da computação, informática, tecnologia da informação, TI. Foram analisados 63 artigos. Os resultados mostram que as meninas do ensino médio ainda não conhecem bem a Computação, há receio quanto aos estereótipos dessa área ser masculina, sobre mulheres serem menos capazes e pouco representadas. Em sua maioria, os trabalhos relataram atividades práticas utilizando diferentes ferramentas, metodologias e estratégias para disseminar informações sobre a Computação e permitir que alunas do ensino médio vivenciem aspectos da área. Prevalece o uso de oficinas e palestras para abordar sobre as profissões da área, trabalhar a história das mulheres na Computação, bem como atividades sobre introdução a programação, desenvolvimento aplicativos e montagem de robôs. Conclui-se que a parceria entre universidades e escolas de ensino básico, principalmente as públicas, permite que as meninas possam compreender melhor as profissões da área da Computação. Isso permite que se visualizem na área futuramente, bem como podem conhecer mulheres estudantes de graduação e profissionais, sentindo-se representadas e empoderadas nesse processo.
\end{abstract}

Palavras-Chave: Meninas; Gênero; Ensino Médio; Computação; Informática; Revisão Sistemática.

\begin{abstract}
The insertion of women in Computing presents challenges that refer to gender issues. In areas such as technology, it is still evident that female representation is reduced compared to men. Literature shows factors that attract and diminish girls in the subjects, courses, and professions of Computing. Studies and interventions that seek to encourage girls and young people to work in Computing can to increasing the insertion of women in professional practice. This work aims to analyze factors related to the lower female presence in Computer courses and initiatives used to attract girls to this area. The methodology was a Systematic Literature Review and descriptors used were: girls, students, high school, computer science, informatics, information technology, IT. Then, sixty-three articles were analyzed. The results show that high school girls still do not know well the area of Computing. They have concerns about the stereotypes of this area being male, about women being less capable and underrepresented. Most of the works reported practical activities using tools, methodologies, and strategies to disseminate Computing and allow high school students to experience aspects of the area. Prevails the use of workshops and lectures to address the professions in the area, shows the history of women in Computing, and activities about programming, application development, and building robots. Thus, the partnership between

Cite as: Menezes, S. K. O., \& Santos, M. D. F. (2021). Gender in Computer Education in Brazil and the Entry of Girls into the Area - A Systematic Review of Literature (Gênero na Educação em Computação no Brasil e o Ingresso de Meninas na Área - uma Revisão Sistemática da Literatura). Brazilian Journal of Computers in Education (Revista Brasileira de Informática na Educação - RBIE), 29, 456-484. DOI: 10.5753/RBIE.2021.29.0.456
\end{abstract}


universities and schools allows the girls to understand better the professions of Computing. They can visualize themselves in Computing in the future; meet women, undergraduate students and professionals; and feeling represented and empowered in this process.

Keywords: Girl; Gender; High School; Computing; Informatics; Systematic Review.

\section{Introdução}

A inserção das mulheres na área da Computação apresenta desafios que envolvem questões de gênero. Conforme Grossi et al. (2016, p. 18), "o afastamento das meninas nas carreiras científicas ditas como duras pode estar associado à edificação social do gênero". Em relação às mulheres, foi construída historicamente e socialmente a associação de características relacionadas à delicadeza e à afetividade. Enquanto aos homens são atribuídas características opostas de disputa, objetividade e racionalidade. De modo que, esses estereótipos também estigmatizam a mulher no cenário científico. Sobre o perfil no campo científico no Brasil, prevalece a participação feminina nas Ciências Humanas e a menor participação nas Ciências Exatas. A presença masculina se destaca em áreas como Engenharias, Computação e Física (Grossi et al., 2016; Nascimento, 2016). Tais aspectos apontam a necessidade de investigar os fatores que contribuem para essa configuração a qual incide desde o Ensino Básico até o Ensino Superior em relação às mulheres no Brasil. Como motivação de pesquisa, este trabalho foca no cenário do Ensino Médio em relação à escolha de meninas pela área da Computação.

\section{Lima (2013, p. 795) aponta que para}

compreender a relação entre ciência e mulheres, é impossível desconsiderar as relações sociais de gênero historicamente construídas. Apesar dos avanços das mulheres em diversas áreas e profissões, a ciência moderna ainda é caracterizada como masculina e exclui as mulheres de diversas formas, seja pela manutenção de redutos de homens, como acontece nas engenharias, na física, na matemática e na computação, seja pela invisibilidade de seus feitos.

Segundo Abbate (2003), apesar das mulheres tradicionalmente não serem encorajadas a se interessarem por determinadas carreiras, elas também se inserem na área da Computação desempenhando o trabalho com entusiasmo e competência. Ainda, ressalta-se que a história das mulheres na Computação não foi amplamente divulgada (Abbate, 2003; Lima, 2013; Schwartz et al., 2006). De acordo com Amaral et al. (2017, p. 859), "as desigualdades entre os sexos, no que se refere à capacidade de produzir conhecimento, são construídas ao longo do tempo, sendo, primeiramente, construídas na família e na escola". Ainda, segundo Payton e Berki (2019), a visão passada pela mídia sobre estereótipos femininos e masculinos nas áreas das Ciências e Matemática cria um estereótipo de como "um cientista deve parecer". Alguns deles são sobre as mulheres serem piores em matemática e ciências que os homens e aspectos antissociais de personalidade atribuídos a cientistas. "A mudança de pensamento da sociedade é fundamental para o desenvolvimento mais democrático das ciências, no qual homens e mulheres tenham as mesmas oportunidades de participação e crescimento" (Schwartz et al, 2006, p. 263).

Sobre a formação acadêmica no Brasil, em pessoas entre 27 e 30 anos de idade, a taxa de conclusão no Ensino Médio em 2016 de mulheres foi de 71,3\% e dos homens foi de 59\%. Em relação ao Ensino Superior, a taxa de conclusão de mulheres foi de $22,1 \%$ e dos homens foi de $16,7 \%$. Sobre a taxa de Ensino Superior completo, por sexo, segundo grupos de idade, entre 25 e 44 anos, tem-se $21,5 \%$ das mulheres e $15,6 \%$ dos homens. Desse modo, nota-se que em relação à educação as mulheres apresentam maior grau de instrução que os homens (Instituto Brasileiro de Geografia e Estatística - IBGE, 2016).

Contudo, ao analisar o acesso ao mercado de trabalho observa-se que essas taxas se modificam significativamente. Conforme o IBGE (2016), a taxa de participação na força de trabalho para pessoas de 15 a 24 anos de idade foi de $48 \%$ para as mulheres e $60,7 \%$ para os 
homens. Sobre a participação das mulheres nos cargos gerenciais, tem-se 37,8\%. Com isso, é preciso ainda um amplo e contínuo processo de sistematização de estratégias para que as mulheres ocupem espaços de trabalho na mesma proporção que os homens, além de cargos de liderança que ainda são em sua maioria atribuídos a homens por considerar competências "masculinas" para o perfil de atuação.

Conforme o IBGE (2019), em 2019, 85,7\% da população com 14 anos ou mais de idade realizaram afazeres domésticos. Em relação às mulheres, o percentual foi de $92,1 \%$ e os homens de 78,6\%. Em média 16,8 horas semanais eram dedicadas a atividades de afazeres domésticos ou cuidado de pessoas, as mulheres apresentam em média 21,4 horas semanais e homens em média 11,0. De forma que, muitas vezes a mulher concilia jornada de trabalho e/ou estudo com a jornada doméstica, ocupando mais tempo com essas atividades que os homens.

Desse modo, estudos e intervenções que possam atrair e incentivar meninas e jovens para atuar na área da Computação pode contribuir para aumentar a inserção de mulheres na área. Além disso, há o desafio da inserção de mulheres em específico na área da docência em Informática e Computação. Nesse contexto, pode-se apontar dois aspectos que podem influenciar para essa inserção. Primeiro aspecto, ainda há uma percepção negativa na sociedade sobre seguir na área de ensino e a escolha profissional pela docência não é uma prioridade entre estudantes. Segundo aspecto, com base em Lima (2013), há menor número de mulheres na Computação, ser professora na área implica enfrentar estereótipos com relação à competência para ensinar e ser produtiva na área.

Além disso, nota-se uma dificuldade em obter artigos sobre a presença feminina na Computação em bases de dados de periódicos que abrangem áreas como a Educação, a Computação e a Psicologia. Esta revisão se diferencia de outras revisões publicadas em eventos científicos, devido ao seu objeto de pesquisa, desenho metodológico e busca de uma reflexão aprofundada da temática. Os trabalhos publicados em eventos científicos são trabalhos mais sucintos, também devido ao próprio formato de apresentação e publicação dos mesmos.

Desse modo, esta RSL pretende contribuir para a Informática na Educação evidenciando os aspectos apontados na literatura sobre os motivos para os índices de mulheres na área da Computação ainda serem significativamente menores em relação aos homens e o que tem sido feito para mudar essa realidade. Esse conhecimento é relevante para buscar alternativas viáveis para a inserção e permanência de mulheres na área, as quais precisam de iniciativas sistemáticas desde o Ensino Básico até o Ensino Superior. A base da pirâmide está na Educação Básica, nesse sentido ações que incentivem a inserção do Pensamento Computacional no Ensino Infantil, Fundamental e Médio podem ter efeitos promissores para diminuir desigualdades de gênero e fazer as meninas se familiarizarem com a área e cogitarem a Computação como escolha profissional no futuro.

Nesse sentido, habilidades de raciocínio lógico, resolução de problemas e criatividade fazem parte do desenvolvimento humano, as quais precisam ser estimuladas ao longo da infância até a vida adulta. De forma que, ressalta-se a necessidade de realizar estratégias de ensino que estimulem e explorem o Pensamento Computacional em diferentes níveis de ensino. Segundo Wing (2006), o Pensamento Computacional está relacionado também com áreas como a Matemática e a Engenharia. Ele auxilia as capacidades de leitura, escrita e aritmética e fundamenta a resolução de problemas na Ciência da Computação e diversas outras áreas. Considera-se que os fundamentos da Matemática, como parte de todas as ciências, e o Pensamento Computacional interagem com o mundo real.

Assim, o objetivo deste trabalho é identificar fatores relacionados à menor presença feminina em cursos de Computação no Brasil e quais iniciativas são utilizadas para atrair 
meninas do ensino médio para essa área. Para isso, foi utilizada uma Revisão Sistemática da Literatura (RSL).

\section{Presença feminina na área da Computação}

$\mathrm{Na}$ história da Computação, há mulheres que foram pioneiras e tiveram uma significativa participação no desenvolvimento da área. Entretanto, estas ainda têm suas histórias pouco conhecidas, sendo as figuras masculinas fortemente consideradas na representação do avanço da área. Dentre algumas figuras femininas, há Augusta Ada Byron, conhecida como Lady Lovelace, matemática considerada a primeira programadora da história, e Grace Murray Hopper, que contribuiu no desenvolvimento da linguagem COBOL e no desenvolvimento do primeiro compilador (Fonseca Filho, 2007; Lima, 2013; Schwartz et al., 2006). Recentemente, a jovem cientista Katherine Bouman, conhecida por Katie, doutora em Engenharia Elétrica e Ciência da Computação pelo MIT (Massachusetts Institute of Technology) criou um algoritmo que foi utilizado na captura da primeira imagem de um buraco negro (BBC, 2019).

Segundo Martins et al. (2019), em uma pesquisa realizada com discentes e egressas de cursos de Sistemas de Informação (SI), Bacharelado em Ciência da Computação (BCC) e Licenciatura em Ciência da Computação (LCC) foram analisados os fatores que atraem e afastam mulheres da área de Tecnologia da Informação (TI). Dentre os fatores que atraem e motivam estão: mostrar que TI também é para meninas; projetos que apoiem as mulheres na área; incentivo de mulheres que já estão na área; disponibilidade de cursos próximos ao local onde as alunas residem; gostar da área; servir de exemplo para outras mulheres; contribuir para o desenvolvimento tecnológico; já trabalhar com TI; apoio de familiares, amigos, professores; exemplos de sucesso na área; contribuir para o desenvolvimento tecnológico, dentre outros fatores.

Sobre os fatores que diminuem o interesse estão: dificuldades e reprovações em disciplinas; pressão psicológica; discriminação de gênero; falta de apoio de professores do curso; carga horária excessiva; pouca experiência prática ao longo do curso; pouco conhecimento sobre o curso antes de entrar; falta de recursos para continuar no curso (Martins et al., 2019). Ainda, Posser e Teixeira (2016) evidenciam a diferença significativa entre o número de homens e mulheres no mercado de trabalho. Sobre esse aspecto buscam identificar motivos para que exista essa diferença. Dentre alguns motivos identificados estão o preconceito e estereótipos sobre Tecnologia da Informação ser para homens, falta de estímulos durante a infância e juventude, desinteresse ou medo de investir na área e a associação de que as mulheres têm habilidades relacionadas com a área de humanas.

Para visualizar a presença de mulheres na área da Computação, foi realizada consulta na Plataforma Nilo Peçanha (2020), de modo a obter a quantidade de estudantes na rede federal de ensino, especificamente no curso técnico em cursos de Informática, em todo o Brasil. Na plataforma foram selecionados: o tipo de curso (Técnico); nome do curso (Técnico em Computação Gráfica, Técnico em Desenvolvimento de Sistemas, Técnico em Informática, Técnico em Informática para Internet, Técnico em Manutenção e Suporte em Informática, Técnico em Programação de Jogos Digitais, Técnico em Redes de Computadores); o tipo de oferta (Integrado e Subsequente); a modalidade de ensino (Educação a distância e Educação presencial); eixo tecnológico (Informática e Comunicação); o subeixo tecnológico (Informática). A plataforma apresenta a visualização das porcentagens conforme a faixa etária. Em relação ao sexo, em 2017, de um total de 76.130 matrículas, 28.069 (36,86\%) eram do sexo feminino; em 2018, do total de 72.288 matrículas, 27.607 (38,19\%) eram do sexo feminino; e em 2019, do total de 73.373 matrículas, $29.203(39,80 \%)$ eram do sexo feminino. De modo geral, foram obtidos os dados que constam na Tabela 1. 
Tabela 1 - Quantidade e faixa etária de mulheres e homens estudantes matriculadas/os na Rede Federal de Educação Profissional, Científica e Tecnológica. Fonte: Plataforma Nilo Peçanha (2020).

\begin{tabular}{|c|c|c|c|c|c|c|c|c|c|c|c|c|}
\hline \multirow{2}{*}{$\begin{array}{l}\text { Ano } \\
\text { Base }\end{array}$} & \multicolumn{12}{|c|}{ Mulheres } \\
\hline & Total & $\begin{array}{c}\text { Menor de } \\
14 \\
\text { anos } \\
\end{array}$ & $\begin{array}{c}15 \text { a } \\
19 \\
\text { anos }\end{array}$ & $\begin{array}{c}20 \text { a } \\
24 \\
\text { anos }\end{array}$ & $\begin{array}{c}25 \text { a } \\
29 \\
\text { anos }\end{array}$ & $\begin{array}{c}30 \text { a } \\
34 \\
\text { anos } \\
\end{array}$ & $\begin{array}{c}35 \text { a } \\
39 \\
\text { anos }\end{array}$ & $\begin{array}{c}40 \text { a } \\
44 \\
\text { Anos }\end{array}$ & $\begin{array}{c}45 \text { a } \\
49 \\
\text { anos } \\
\end{array}$ & $\begin{array}{c}50 \text { a } \\
54 \\
\text { anos } \\
\end{array}$ & $\begin{array}{c}55 \text { a } 59 \\
\text { anos }\end{array}$ & $\begin{array}{c}\text { Maior de } 60 \\
\text { anos }\end{array}$ \\
\hline 2017 & 28.069 & 146 & 17.441 & 4.628 & 2.211 & 1.454 & 982 & 591 & 354 & 163 & 64 & 35 \\
\hline 2018 & 27.607 & 112 & 19.687 & 4.024 & 1.486 & 938 & 642 & 379 & 180 & 103 & 40 & 16 \\
\hline 2019 & 29.203 & 81 & 21.556 & 4.025 & 1.361 & 871 & 602 & 378 & 172 & 103 & 39 & 15 \\
\hline \multirow{2}{*}{$\begin{array}{l}\text { Ano } \\
\text { Base }\end{array}$} & \multicolumn{12}{|c|}{ Homens } \\
\hline & Total & $\begin{array}{c}\text { Menor de } \\
14 \\
\text { anos } \\
\end{array}$ & $\begin{array}{c}15 \text { a } \\
19 \\
\text { anos }\end{array}$ & $\begin{array}{c}20 \text { a } \\
24 \\
\text { anos }\end{array}$ & $\begin{array}{c}25 \text { a } \\
29 \\
\text { anos }\end{array}$ & $\begin{array}{c}30 \text { a } \\
34 \\
\text { anos }\end{array}$ & $\begin{array}{c}35 \text { a } \\
39 \\
\text { anos }\end{array}$ & $\begin{array}{c}40 \text { a } \\
44 \\
\text { Anos }\end{array}$ & $\begin{array}{c}45 \text { a } \\
49 \\
\text { anos } \\
\end{array}$ & $\begin{array}{c}50 \text { a } \\
54 \\
\text { anos } \\
\end{array}$ & $\begin{array}{c}55 \text { a } 59 \\
\text { anos }\end{array}$ & $\begin{array}{c}\text { Maior de } 60 \\
\text { anos }\end{array}$ \\
\hline 2017 & 48.061 & 224 & 28.995 & 8.334 & 4.028 & 2.689 & 1.742 & 992 & 526 & 303 & 126 & 102 \\
\hline 2018 & 44.681 & 134 & 30.993 & 7.126 & 2.647 & 1.648 & 1.010 & 513 & 294 & 149 & 82 & 49 \\
\hline 2019 & 44.170 & 106 & 31.964 & 6.878 & 2.224 & 1.342 & 792 & 428 & 227 & 104 & 61 & 44 \\
\hline
\end{tabular}

Na referida plataforma, estavam disponíveis os anos base 2017, 2018 e 2019. Observa-se que a quantidade de homens ainda supera a quantidade de mulheres. Ao longo desses três anos houve um aumento sutil de mulheres nos cursos técnicos em Informática. Contudo, ainda há baixo índice de mulheres que seguem na área após a conclusão do curso. Nota-se também que houve aumento na quantidade de homens no curso ao longo desse período, esse dado é coerente com o cenário histórico onde a presença de homens em cursos de Informática mantém estabilidade e permanece significativamente maior em relação à presença de mulheres.

Segundo Nunes (2018), no documento Educação Superior em Computação Estatísticas 2018, é possível observar na Figura 1 a evolução quanto à entrada em cursos de Computação por gênero entre 2001 e 2018.

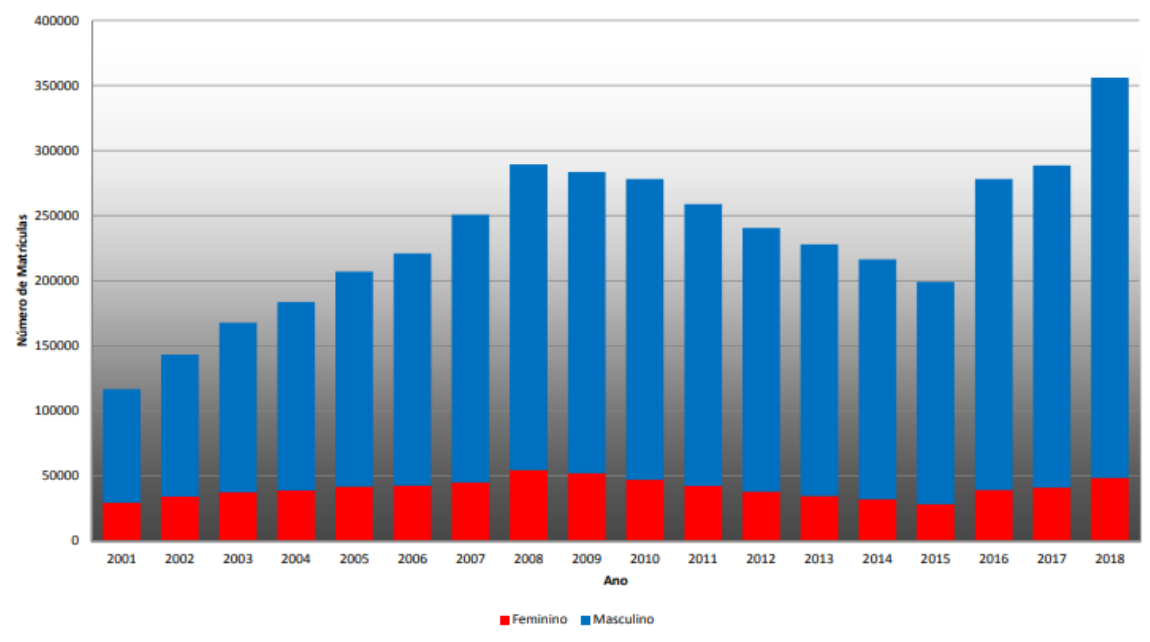

Figura 1 - Evolução das matrículas de estudantes por gênero entre 2001 e 2018. Fonte: Nunes (2018).

Os dados da Figura 1 mostram claramente o quanto a quantidade de mulheres (em vermelho) em cursos de Computação ainda é discrepante se comparada a de homens (em azul). Em áreas como a tecnologia ainda é evidente que a atuação feminina é reduzida em comparação ao número de homens (Posser \& Teixeira, 2016). Figueiredo e Maciel (2016, p. 2729) apontam que "o desafio maior está em transformar estas mulheres de simples consumidoras de tecnologia em produtoras de tecnologia, participando ativamente do projeto e desenvolvimento dos produtos".

Conforme dados do Resumo Técnico do Censo da Educação Superior (2018), foram observados os 20 maiores cursos. Dentre eles 14 apresentam predominância feminina:

Pedagogia (92,5\% de mulheres), Serviço Social (89,9\%), Nutrição $(84,1 \%)$, Enfermagem $(83,8 \%)$,

Psicologia $(79,9 \%)$, Fisioterapia $(78,3 \%)$, Gestão de Pessoas (77,9\%), Odontologia $(71,7 \%)$, 
Farmácia (71,3\%), Arquitetura e Urbanismo (66,5\%), Medicina (59,0\%), Contabilidade (56,5\%), Direito $(55,5 \%)$ e Administração $(54,4 \%)$. Os cursos (rótulos) com predominância masculina são: Engenharia Mecânica (89,8\% de homens), Sistema de informação (86,2\%), Engenharia Civil $(69,7 \%)$, Engenharia de Produção $(65,6 \%)$, Educação Física $(65,1 \%)$ e Educação Física Formação de Professor $(60,3 \%)$.

Sobre tais dados, nota-se a prevalência da presença feminina em cursos de Ciências Humanas e Ciências da Saúde. Dentre os cursos com maior presença masculina 4 são da área de Exatas. Nesse sentido, vale ressaltar como na sociedade há profissões socialmente construídas e atribuídas às mulheres e aos homens, de modo que elas repercutem na divisão sexual e social do trabalho (Cisne, 2015; Lima, 2013).

\section{Trabalhos Relacionados}

Na busca por trabalhos de revisão sistemática sobre a inserção de mulheres na Computação, em específico sobre meninas, foram obtidos dois trabalhos relacionados às meninas no ensino básico e três mais abrangentes sobre incentivo de mulheres para aderirem à área. A seguir são discutidos os cinco trabalhos selecionados. No trabalho de Mattos et al. (2016) foi realizado um mapeamento sistemático e foram analisados estudos sobre o Scratch como ferramenta para incentivar meninas na definição de uma profissão. Foram analisados 5 artigos. Em todos os trabalhos foi utilizado workshop. As autoras verificaram que apenas essa abordagem é insatisfatória, sendo necessários estudos que explorem outras abordagens. Apesar dos estudos apontarem que o uso da linguagem teve aspecto positivo sobre as meninas, não há uma investigação em longo prazo se o interesse foi mantido na área de tecnologia.

Moreira et al. (2016) analisaram métodos e ferramentas para atrair meninas do Ensino Fundamental e Médio para a Computação. Foram analisados 23 artigos (20 dos Estados Unidos, 2 da Arábia Saudita e 1 da Alemanha), entre 2010 e 2015. Grande parte das atividades foi realizada em acampamentos de verão nos Estados Unidos. Destacaram-se atividades com jogos educativos e uso de ferramentas como Alice, Lego Mindstorm, Scratch e MIT App Inventor (aplicação desenvolvida pelo Massachusetts Institute of Technology), gratuitas exceto pelo Lego. A maioria dos estudos foi apenas com meninas e os conteúdos foram sobre ensino de programação, desenvolvimento de aplicativos, robótica, jogos educativos e palestras.

Cesario et al. (2017) apresentaram uma análise dos trabalhos publicados no X Women in Information Technology (WIT). Os resultados mostraram a existência de projetos no Brasil para incentivar a participação de mulheres em áreas da Computação, os quais são em sua maioria desenvolvidos por instituições públicas de Ensino Superior. Foram identificados doze projetos nos artigos analisados, onde oito estavam vinculados ao Programa Meninas Digitais. Foi identificada a prevalência de oficinas e palestras nas ações realizadas pelos projetos.

Nunes et al. (2016a) realizaram um mapeamento sistemático sobre iniciativas brasileiras que fomentam a entrada de mulheres na área da Computação. Os dados foram coletados em agosto de 2014. Foram identificados 16 sites de iniciativas brasileiras relacionadas ao tema. Os workshops e palestras são as iniciativas mais utilizadas. Também aparecem blogs dentre as iniciativas. As autoras enfatizam que outras pesquisas são necessárias para mapear outras iniciativas que não foram identificadas. Nunes et al. (2016b) realizaram um mapeamento sistemático sobre iniciativas estrangeiras que fomentam a entrada de mulheres na área da Computação no mundo. Os dados foram coletados em agosto de 2014. Foram identificadas 59 iniciativas internacionais em sites e a partir deles descritas ações como workshops, palestras, fóruns, tutoria, cursos, conferências, tutoria, consultoria, competição, jogos de ensino, desenvolvimento de software, blogs, dentre outros. A maioria das iniciativas (56\%) foi identificada nos EUA. 
Esta revisão sistemática de literatura se diferencia dos trabalhos relacionados acima apresentados e explora de modo abrangente eventos científicos brasileiros da área da Computação e bases de periódicos para obter um panorama nacional sobre as ações voltadas para incentivar a entrada de meninas na área da Computação e os fatores associados à baixa presença de mulheres na área. Quanto ao âmbito nacional, espaço de tempo de busca dos trabalhos e mais especificamente sobre o Ensino Médio, também se diferenciam desta revisão, não havendo outro identificado com o mesmo propósito.

\section{Metodologia}

Nesta pesquisa foi realizada uma Revisão Sistemática de Literatura (RSL), que busca identificar, avaliar e analisar trabalhos relevantes para uma questão de pesquisa específica. A revisão foi baseada no método aplicado por Jesus et al. (2019) e Kitchenham (2007), com adaptações. Foi realizada a busca de artigos em fevereiro de 2021. O foco desta RSL são pesquisas realizadas no Brasil, em trabalhos futuros pretende-se analisar produções em âmbito internacional e também nos níveis de Ensino Fundamental e Superior para ampliar e aprofundar a discussão sobre a temática deste trabalho. Foi estabelecido o período de busca entre 2011 e 2020, em eventos de Computação: Anais do Congresso da Sociedade Brasileira de Computação (CSBC), no evento base Women in Information Technology (WIT) e nos Anais do Workshop sobre Educação em Computação (WEI); Anais dos Workshops do Congresso Brasileiro de Informática na Educação (CBIE); Anais do Workshop de Informática na Escola (WIE); Anais do Simpósio Brasileiro de Informática na Educação. Em relação à escolha dos eventos, o CSBC e o CBIE são eventos de referência na área da Computação, tendo uma significativa abrangência e diversidade de publicações que envolvem a Educação e Computação.

Também foram consultados os seguintes periódicos e repositórios: Revista Brasileira de Informática na Educação (RBIE); Revista Novas Tecnologias na Educação (RENOTE); Informática na educação: teoria \& prática (IETP); The Scientific Electronic Library Online (SciELO); Portal de Periódicos da Coordenação de Aperfeiçoamento de Pessoal de Nível Superior (CAPES); IEEE Xplore e Google Scholar. A escolha foi devido à relevância e possibilidade de acesso a trabalhos em diferentes periódicos, em áreas como a Educação, Computação e Psicologia. No IEEE Xplore a busca também focou artigos de experiências realizadas no Brasil.

\subsection{Questões de Pesquisa (QP) e String de Busca}

O trabalho aqui apresentado busca responder as seguintes questões de pesquisa:

- QP1: Quais os fatores apontados para a menor presença feminina em cursos de Computação?

- QP2: Quais as iniciativas para atrair meninas para cursos de Computação?

Para a busca de publicações nas bases de dados foram utilizados os seguintes indexadores na string de busca: "meninas", "alunas", "estudantes", "ensino médio", "ciência da computação", "TI", "tecnologia da informação", "informática", termos que se relacionam diretamente com as questões de pesquisa. Os operadores lógicos AND e OR foram utilizados para combinar os indexadores, obedecendo às regras de cada base consultada. No IEEE Xplore, considerando que é uma base internacional, foram utilizados: "girls", "high school", "computer science", "IT", "information technology", "computing”, "Brazil”". 


\subsection{Critérios de Seleção de Trabalhos Científicos}

A busca limitou os resultados ao período de 2011 a 2020. Esse período foi estabelecido para obter um panorama nacional sobre a temática e também levando em conta o período de publicação de trabalhos disponível em eventos consultados para esta RSL. Sobre a busca realizada nas bases supracitadas, foram selecionados 63 artigos. A Tabela 2 mostra a quantidade de resultados obtidos em cada uma das bases antes e depois de aplicar os critérios de inclusão e exclusão.

Foi necessário definir critérios para identificar os trabalhos a serem analisados, de acordo com sua relevância para esta pesquisa. Foram aplicados os seguintes critérios de inclusão: artigos que abordam sobre iniciativas relacionadas à Computação voltadas para meninas do Ensino Médio no Brasil; artigos que abordam sobre fatores para a menor presença feminina em cursos de Computação no Brasil; artigos completos e artigos curtos; artigos publicados em periódicos ou anais de eventos; artigos em português, inglês ou espanhol; publicados entre 2011 a 2020. Os critérios de exclusão foram: artigos duplicados; resumos publicados em eventos científicos; artigos que não estavam relacionados à temática; artigos apenas sobre o Ensino Superior; artigos apenas sobre o Ensino Fundamental; artigos que realizaram estudos no Ensino Médio e não abordaram sobre o gênero feminino; revisão sistemática; capítulo de livro; editorial; artigos sem acesso ao arquivo digital.

No processo de busca foi realizada a triagem do material seguindo os critérios de inclusão e exclusão definidos. O processo foi composto por três etapas onde foram observados os referidos critérios. Na primeira etapa utilizando filtros das próprias bases: foram excluídos artigos que não estavam no período temporal estabelecido para esta pesquisa; que não disponibilizavam o texto para acesso; que não eram relacionados ao Brasil; que não estavam em português, inglês ou espanhol; materiais que não fossem artigos (capítulo de livro, resumos, editorial). A segunda etapa foi a leitura do título, resumo e palavras-chave para eliminar artigos que não fossem relacionados aos critérios de inclusão. A última etapa foi a leitura completa dos artigos para garantir a exclusão de artigos que não atendessem aos critérios de inclusão estabelecidos.

Nos eventos, a busca levou em conta o período temporal disponível nos sites consultados, conforme as opções disponíveis nos filtros avançados. Nos Anais do WIT foi possível pesquisar de 2016 a $2020^{1}$. Nos Anais do Workshop sobre Educação em Computação (WEI) de 2014 a $2020^{2}$. Nos Anais dos Workshops do Congresso Brasileiro de Informática na Educação de 2012 a $2020^{3}$. No Workshop de Informática na Escola (WIE) de 2011 a 2020. No site estavam disponíveis a partir de $2003^{4}$. Nos anais do SBIE de 2011 a 2020, disponíveis a partir de $2001^{5}$. Assim, foram obtidos 129 resultados, dos quais 76 foram excluídos por não se relacionarem a nenhuma das questões de pesquisa. Com a análise dos títulos e resumos, obteve-se 53 após aplicar os critérios de inclusão e exclusão. Após a leitura completa, obteve-se 51 artigos a partir dos eventos CBIE e CSBC. Na SciELO foram recuperados 156 resultados. Com a aplicação dos filtros da base (tipos de recurso (artigos), data de publicação (2011 a 2020) e tópico (Brasil)) foram obtidos 91 resultados. No Portal de Periódicos da Capes foram recuperados 1.547 resultados. Com a aplicação dos filtros da base (tipos de recurso (artigos), data de publicação (2011 a 2020) e tópico (Brasil)) foram obtidos 147 resultados. Nessas duas amostras não foram identificados trabalhos que atendessem aos critérios de inclusão.

\footnotetext{
${ }^{1}$ Anais do WIT (2016-2020). Recuperado em: https://sol.sbc.org.br/index.php/wit/search/search

${ }^{2}$ Anais do Workshop sobre Educação em Computação (2014-2020). Recuperado em: https://sol.sbc.org.br/index.php/wei/search/search

${ }^{3}$ Anais dos Workshops do Congresso Brasileiro de Informática na Educação (2012-2019). Recuperado em: https://sol.sbc.org.br/index.php/wcbie/search/search. CBIE 2020. Recuperado em: https://www.br-ie.org/pub/index.php/wcbie/index

${ }^{4}$ Workshop de Informática na Escola (WIE) (2011 a 2019). Recuperado em: https://br-ie.org/pub/index.php/wie/index . WIE 2020 Recuperado em: https://sol.sbc.org.br/index.php/wie/search/search

${ }^{5}$ SBIE de 2011 a 2019. Recuperado em: https://www.br-ie.org/pub/index.php/sbie/search/search. SBIE 2020. Recuperado em: https://sol.sbc.org.br/index.php/sbie/search/search
} 
Na RBIE, RNOTE e IETP não houve trabalhos relacionados. Na busca no Google Scholar foram obtidos 104.000 resultados, com o filtro de relevância dos mesmos e no período de 2011 a 2020. Foram analisados os resultados das primeiras 20 páginas, com um total de 195 resultados. Nesses resultados, em relação à busca no WIT foram observadas 21 repetições. Foram selecionados 8 artigos relacionados à pesquisa, sem as repetições. Dentre eles, foram excluídos 3 trabalhos. Assim, foram 5 trabalhos selecionados, um dos Workshops do CBIE e um dos Workshop sobre Educação em Computação (WEI), os quais não apareceram nos mecanismos de buscas anteriores diretamente no site dos anais destes eventos. No IEEE Xplore foram obtidos 8 artigos e um foi excluído por não ser relacionado a meninas na Computação.

Tabela 2 - Buscas nas bases de dados.

\begin{tabular}{|c|c|c|c|c|}
\hline Bases & $\begin{array}{c}\text { Total de } \\
\text { arquivos } \\
\text { recuperados }\end{array}$ & $\begin{array}{c}\text { Após análise } \\
\text { de critérios de } \\
\text { inclusão/ } \\
\text { exclusão }\end{array}$ & $\begin{array}{c}\text { Após } \\
\text { análise de } \\
\text { títulos e } \\
\text { resumos }\end{array}$ & $\begin{array}{c}\text { Após } \\
\text { leitura } \\
\text { integral }\end{array}$ \\
\hline CSBC - Anais do Women in Information Technology (WIT) & 41 & 39 & 39 & 39 \\
\hline CSBC - Anais do Workshop sobre Educação em Computação (WEI) & 11 & 4 & 4 & 4 \\
\hline $\begin{array}{l}\text { CBIE - Anais dos Workshops do Congresso Brasileiro de Informática na } \\
\text { Educação }\end{array}$ & 29 & 2 & 2 & 2 \\
\hline CBIE - Anais do Workshop de Informática na Escola (WIE) & 26 & 6 & 6 & 6 \\
\hline CBIE - Anais do Simpósio Brasileiro de Informática na Educação & 22 & 0 & 0 & 0 \\
\hline Revista Brasileira de Informática na Educação (RBIE) & 0 & 0 & 0 & 0 \\
\hline Revista Novas Tecnologias na Educação (RENOTE) & 0 & 0 & 0 & 0 \\
\hline Informática na educação: teoria \& prática (IETP) & 1 & 0 & 0 & 0 \\
\hline Portal de Periódicos da CAPES & 147 & 0 & 0 & 0 \\
\hline SciELO & 91 & 0 & 0 & 0 \\
\hline Google Scholar & 195 & 7 & 5 & 5 \\
\hline IEEE Xplore & 8 & 7 & 7 & 7 \\
\hline TOTAL & 571 & 65 & 63 & 63 \\
\hline
\end{tabular}

Após a leitura integral dos artigos selecionados, foram realizadas classificações: A. Empírico/Conceitual (Empíricos - pesquisas que apresentam atividades práticas ou trabalhos com amostras populacionais - e Conceituais - trabalhos que apresentam discussões teóricas referentes ao tema); B. Público Alvo (nível de educação formal das participantes); C. Instrumentos de Pesquisa (instrumentos de pesquisa foram utilizados para coleta e análise de dados); D. Ferramentas (ferramentas utilizadas nas atividades para atrair meninas para informática); E. Estratégias e metodologias (quais as alternativas de execução das propostas); F. Origem dos Estudos (regiões do Brasil, estados brasileiros e instituições de origem dos estudos analisados); G. Ano de publicação (classificação temporal dos trabalhos); H. Descrição dos trabalhos selecionados (categorias com base nas questões de pesquisa).

\section{Resultados}

Nesta seção, os artigos selecionados foram classificados conforme descrito na metodologia. No final do artigo consta o Apêndice com a tabela onde estão identificados numericamente os artigos desta RSL. Nas subseções a seguir os mesmos encontram-se classificados e utilizam a numeração atribuída a cada um deles. Dentre os trabalhos, 20 resultados são trabalhos completos (ver Apêndice, os trabalhos 6, 23, 26, 30, 41, 42, 44, 45, 46, 47, 48, 49, 50, 51, 52, 53, 54, 55, $56,57)$ e 43 resultados são trabalhos curtos.

\section{A. Empírico/Conceitual}

A partir da análise dos 63 artigos selecionados foram identificados 62 trabalhos empíricos e um trabalho conceitual (13). A maioria dos trabalhos refere-se a atividades práticas ou pesquisa com amostras populacionais. Na subseção H são descritos os trabalhos. 


\section{B. Público Alvo}

Em relação ao público alvo, há estudos que trabalharam com estudantes de mais de um nível de ensino. Foi observado maior número de trabalhos apenas no Ensino Médio. Como esta pesquisa tem foco nesse contexto, todos os trabalhos abordam sobre esse nível de ensino. Também há trabalhos que abordam sobre Ensino Médio ou tem como participantes alunas do Ensino Médio, mas também abrangem outro nível de ensino. A maioria dos estudos $84,1 \%$ foi realizada apenas com alunas de escolas públicas e 15,9\% com alunas de escolas públicas e privadas $(2,10,12$, $18,28,32,33,35,49,50)$. Onze estudos tiveram participantes meninos e meninas $(9,10,16,35$, $38,40,48,54,56,60,61)$ e entraram no escopo desta RSL, pois discutem a participação das meninas nas atividades. Com relação a outros níveis de ensino abrangidos nos trabalhos houve: Ensino Fundamental (19, 28, 36, 52, 54, 57, 62, 63); Ensino Técnico (26, 29, 37, 53, 56, 63) e Graduação $(2,11,39)$.

\section{Instrumentos de Pesquisa}

Grande parte dos trabalhos utilizou o questionário como instrumento na pesquisa. Ele foi utilizado na maioria para levantamento do perfil do público antes das atividades e ao fim das atividades para as participantes realizarem a avaliação. Também foi utilizado para mapear aspectos sobre o interesse sobre a Computação, aspectos que atraem ou não as meninas para a área $(1,10,12,15,18,19,24,25,26,32,35,39,53,55,57,60)$. O questionário foi utilizado para levantamentos, sondagens nas turmas e avaliação de ações $(1,4,5,6,7,8,12,15,16,18$, $19,21,23,25,26,31,32,35,38,39,41,42,43,44,45,46,47,48,51,53,54,55,57,58,60$, $61)$. A entrevista foi utilizada para avaliar aspectos qualitativos $(53,56,61)$.

\section{Ferramentas}

Foi observada uma variedade de ferramentas. MIT App Inventor e Scratch são as mais utilizadas, elas se destacam por serem intuitivas e não é necessário ter conhecimentos mais profundos de programação para utilizá-las. Por isso, são aplicadas no ensino introdutório de programação. De modo geral, as ferramentas identificadas foram: MIT App Inventor $(7,14,23$, 24, 28, 33, 41, 44, 50, 58); Code.org (4, 16, 41); Construct2 (14, 47); C++ (61, 63); Greenfoot (17); HTML/CSS (14, 27, 34, 48, 51); IDE Arduino (30); instrumentos musicais (17); Java (17); jogos de cartas Computasseia (2); Kahoot (45); kit Arduino (20, 38, 63); kit de eletrônica (8, 55, 58); kit LEGO (20, 22, 27, 31, 51, 55, 58); kit ROBO TX Explorer (42); kit Robô Sumô Arduino UR20 (49); Kodu (55, 58); LightBot (24, 41); lixo eletrônico (9); MovieMaker (27); PIC-PAC stop motion (21); Python (63); robôs sparks (20, 61); S4A (30); Scratch (24, 27, 30, 41, 43, 46, 60, 63); Snap Circuits (3); VisualG $(31,47)$.

\section{E. Estratégias e Metodologias}

Foram observadas as estratégias e metodologias utilizadas nos trabalhos, ver Figura 2. Pode-se ver uma diversidade e há trabalhos que apontam o uso de mais de uma estratégia ou metodologia para as atividades. Destacam-se as oficinas $(44,4 \%)$, palestras $(22,2 \%)$ e estudos com levantamentos sobre o interesse de meninas pela Computação $(12,6 \%)$. Foi observada quantidade significativa de trabalhos parceiros do Programa Meninas Digitais da Sociedade Brasileira de Computação $(2,4,5,6,7,8,9,11,12,14,15,16,19,20,21,25,26,30,33,34,36,37$, $39,44,55,58,63)$. 


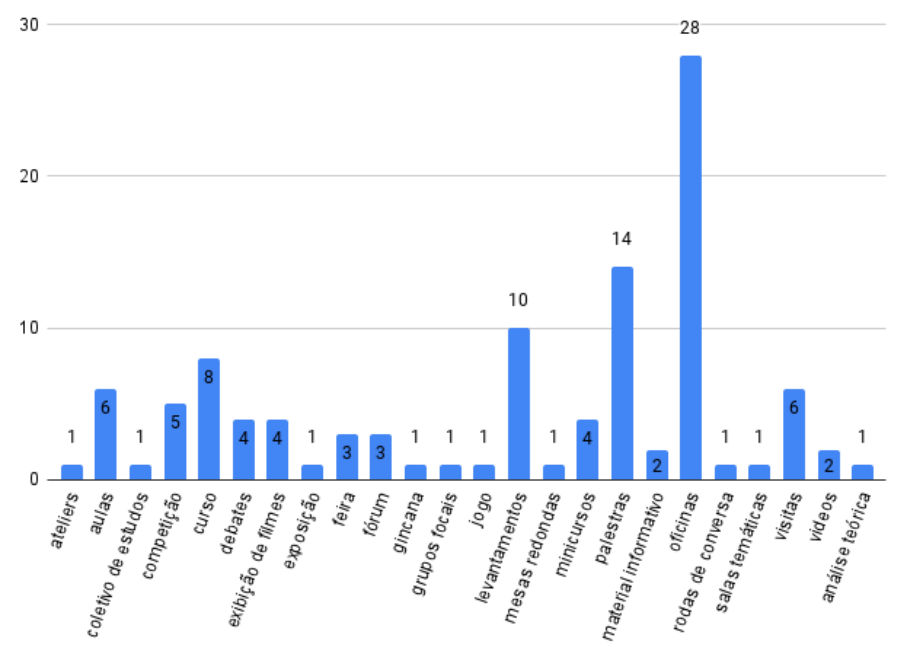

Figura 2 - Estratégias e metodologias. Fonte: Elaboração própria (2021).

\section{F. Origem dos Estudos}

Na Figura 3, observa-se uma distribuição dos estudos por estados brasileiros e instituições as quais os/as autores/as estão vinculados/as, destacam-se universidades e institutos federais. Dentre as regiões, 32,8\% (22) são do Sul; 28,4\% (19) do Centro-Oeste; 22,4\% (15) do Nordeste; $9,0 \%$ (6) do Sudeste; e 7,5\% (5) do Norte.

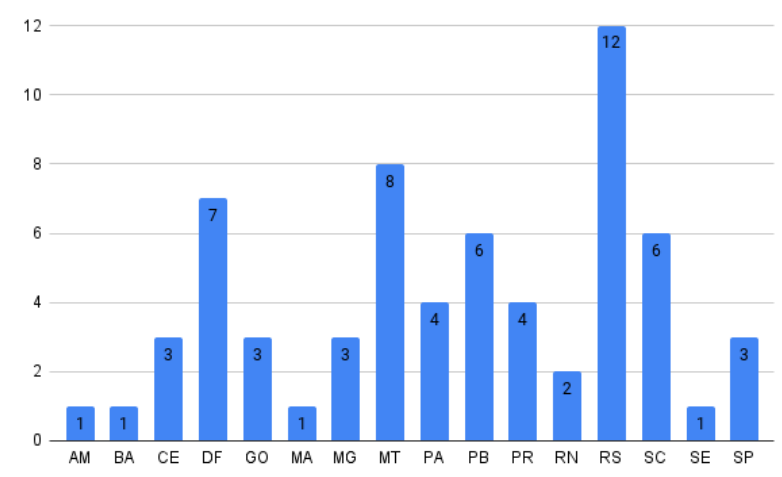

(A)

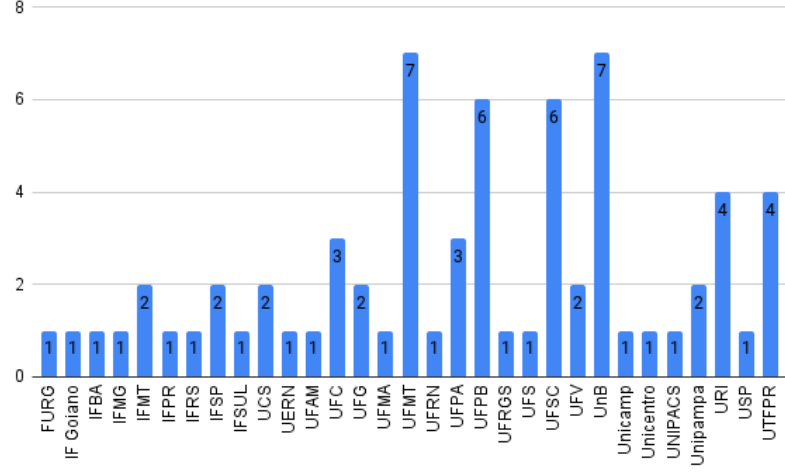

(B)

Figura 3 - (A) Quantidade de publicações por estados brasileiros. (B) Quantidade de publicações por instituições de vínculo dos/as autores/as dos estudos. Fonte: Elaboração própria (2021).

\section{G. Ano de Publicação}

A Figura 4 mostra a quantidade de trabalhos por ano. Destacaram-se os anos de 2020 e 2016.

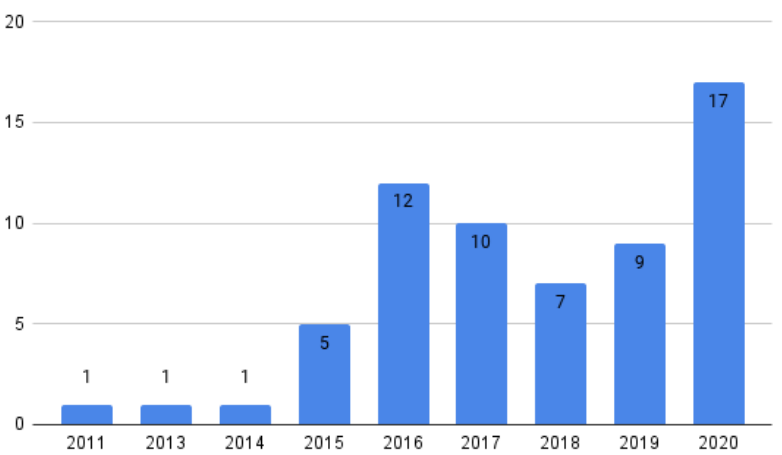

Figura 4 - Quantidade de trabalhos por ano. Fonte: Elaboração própria (2021). 


\section{H. Descrição dos Trabalhos Selecionados}

A seguir os trabalhos selecionados são descritos para compreensão de seus objetivos e aspectos que abordam. Foram organizados em duas categorias: a menor presença feminina na área da Computação e iniciativas para atrair meninas para esta área.

\section{Menor presença feminina na área da Computação}

Foram analisados aportes teóricos sobre as relações de gênero, tecnologia e processo vocacional para discutir como o gênero poderia influenciar o processo vocacional de alunas do ensino médio para o ingresso em cursos superior das áreas de Computação, Engenharias e Tecnologias (CET). Através da literatura, foram identificados aspectos sociais que influenciam na escolha vocacional, dentre eles a baixa autoeficácia que faz as mulheres não optarem por áreas majoritariamente masculinas [13]. Foram realizadas atividades com estudantes do Ensino Médio e ao questionar sobre a inserção feminina na área de TI identificaram que há a existência de insegurança com relação ao ingresso e permanência em cursos superiores dessa área; mesmo interessadas pela área muitas meninas se sentem intimidadas por achar que informática é difícil, que essa área é para homens. As autoras também apontam que elas são apenas duas professoras na instituição em que atuam, em meio a cursos de nível médio e superior, apontando para a baixa representatividade na área [29].

Sobre as razões que dificultam a escolha de mulheres por cursos e carreira das áreas de Ciência, Tecnologia e Computação, o projeto Meninas na Computação, realizou pesquisa em 2016 e 2017 e participaram 254 alunas de $1^{\circ}$ e $2^{\circ}$ anos de duas escolas estaduais de Ensino Médio, na Paraíba. A questão principal investigada foi "Existe algum preconceito ou barreira que impeça ou dificulte o ingresso de mulheres na área de Computação?". Sobre os resultados: 106 acharam que não; 113 responderam que nunca pensaram sobre; 35 responderam que sim. Para as alunas que confirmaram foi questionada a forma de barreira ou preconceito. As categorias observadas foram: machismo (29\%); capacidade $(23 \%)$; há mais homens $(20 \%)$; é coisa de homem (14\%) e outros (14\%). Na categoria intitulada outros surgiram respostas sobre a mulher ser masculinizada ao entrar na área, receber menos que os homens, a mulher ter o papel de cuidar da casa [1].

Para aumentar a visibilidade das mulheres na história da Computação, foi realizada uma ação de inclusão com salas temáticas sobre Computação para alunas do Ensino Médio, no evento Espaço das Profissões, em dois dias, em 2018. A ação foi promovida pelo projeto $A D A s$ da Universidade Federal de Goiás (UFG), denominada "Mulheres na Computação". Foram obtidos 117 questionários respondidos. Foi observado que 40\% das alunas afirmaram que não tinham conhecimento sobre a área. Também foi identificada a dificuldade de gostar de matemática e a expectativa que o curso de Computação seja difícil. Uma das perguntas foi "Você acha que a Computação é uma área masculina?", 76,7\% afirmaram que não e 19\% afirmaram que sim. Sobre os motivos para afirmar que não, as respostas indicam que a Computação é para qualquer pessoa e que a mulher também é capaz, mas também consideram a falta de visibilidade da mulher na área. Sobre os motivos para afirmar que sim, as respostas apontam o machismo, os estereótipos de gênero e a baixa visibilidade de mulheres na área deixar a impressão de que a área é masculina [12].

Em oficinas com estudantes do $1^{\circ}$ ano do Ensino Médio em uma escola pública do Distrito Federal, através da aplicação de questionário, foram investigados os motivos pelos quais as alunas têm menos interesse nas Ciências Exatas. A maioria afirmou que a dificuldade nas disciplinas de Exatas faz com que procurem menos cursos relacionados. Também apontaram a falta de incentivo de professores e pais. Os meninos afirmaram ter mais interesse na área de Exatas por utilizarem computadores e videogames com maior frequência [38]. 
Em uma pesquisa com alunas do $3^{\circ}$ ano do Ensino Médio durante a $7^{\mathrm{a}}$ Edição da Feira Norte do Estudante (FNE), em 2016, o objetivo foi descobrir o que atrai e o que não atrai as meninas para a área de Exatas. As meninas que voluntariamente chegavam ao espaço do Projeto Cunhantã Digital foram convidadas a responder às questões anonimamente. Sobre a escolha por curso superior foram observados os seguintes interesses: 39\% por Ciências Biológicas e da Saúde; 32\% por Ciências Humanas; $28 \%$ por Ciências Exatas e 1\% por Ciências Agrárias. Sobre as razões para escolher a área da TI no vestibular, os pontos mais citados foram: trabalhar com novas tecnologias, mercado de trabalho, salário. O incentivo de família e amigos foi de apenas 7\%. Sobre as razões para não escolher a área da TI no vestibular foram mais citadas: falta de vocação $(60 \%)$, não ter habilidades matemáticas $(37 \%)$ e influência negativa da família e amigos $(25 \%)$ [25].

Em um estudo qualitativo sobre ensino de programação no Ensino Médio. Foi realizada oficina de lógica de programação utilizando Scratch e também aplicado questionário sobre contato com a Computação e a presença de meninas nesse campo. Participaram 6 meninas e 1 menino, entre 15 e 16 anos de idade. Os resultados mostram que há alguns preconceitos sobre o trabalho de mulheres nas Ciências Exatas que são intensificados por questões sociais que influenciam a escolha da profissão. Dentre os aspectos vistos nas respostas das/o alunas/o estão: associação de maior presença masculina na área, as meninas terem interesse por áreas sociais e o interesse dos meninos ser maior pela área desde criança [60].

Em relação à escolha profissional de alunas concluintes do Ensino Médio da região de Paranhana/RS, foi aplicado questionário entre outubro e novembro de 2016 e foram obtidas respostas de 734 alunas. Sobre as respostas: 80\% relataram já ter escolhido uma profissão para seguir; $10 \%$ não haviam decidido e 10\% estavam indecisas. Foram citadas 65 carreiras, em relação às grandes áreas do conhecimento: $29 \%$ da área das Ciências da Saúde; $30 \%$ de Ciências Sociais Aplicadas; 19\% de Ciências Humanas; 7\% de Ciências Agrárias; 5\% da Linguística, Letras e Artes; 3\% de Engenharias; 3\% de Ciências Exatas e da Terra; 2\% de Ciências Biológicas; $2 \%$ outros e $0 \%$ de áreas multidisciplinares. Apenas 2 carreiras citadas pelas alunas estão diretamente relacionadas com TI (analista de sistema e desenvolvedora de jogos) manifestadas nas respostas de 3 jovens [18].

No projeto Meninas.comp: Computação também é coisa de menina o intuito é divulgar a área da Computação para meninas do Ensino Médio no Distrito Federal. Foram realizadas oficinas motivacionais e de eletrônica, desenvolvimento de jogos, fóruns, feiras, coleta de dados sobre a percepção de alunas sobre Computação. Em pesquisa realizada entre 2011 a 2014 foi investigada a percepção de alunas sobre a área e foram obtidos 1.821 questionários preenchidos. Os resultados mostraram que a maioria das meninas considerou a Computação como uma área masculina. Sobre o apoio da família, um número maior afirmou que embora não haja incentivo para seguir na área, também não são proibidas de escolher o curso para o vestibular. Sobre empregabilidade e bom salário, a maioria afirmou que a área oferece tais oportunidades [55].

Foi realizada pesquisa sobre a percepção de meninas do Ensino Fundamental e Médio em Brasília sobre o curso de Ciência da Computação. Essa atividade está vinculada ao projeto Meninas.comp. O questionário foi aplicado entre 2011 a 2014 durante a Semana Nacional de Ciência e Tecnologia (SNCT). Foram obtidas 3.707 respondentes. As autoras observaram que ações realizadas com alunas no Ensino Fundamental podem ter efeito mais promissor que no Ensino Médio, uma vez que nesse nível de ensino as alunas já apresentam seu desejo por profissões definido. Os dados mostram a perda de interesse ao longo dos anos em Computação. Ainda, a necessidade de apoio da família que é muito importante na escolha profissional [19].

Para compreender sobre a falta de interesse de meninas pela área da Computação foi realizada coleta de dados com estudantes do Ensino Médio e Fundamental em dois momentos, outubro de 2011 (1.391 respostas) e julho de 2019 (429 respostas). Os resultados mostraram 
menor interesse da amostra de 2019 em Computação (28,4\%) em relação a 2011 (41,8\%). Sobre o curso ter mais homens, houve uma variação onde diminuiu o número de meninas que afirmaram que no curso a maioria é do sexo masculino. Sobre o apoio da família, em 2011 houve maior número de respostas (47,46\%) que em 2019 (42,2\%). A empregabilidade não foi visualizada como um problema [57].

Também com o intuito de entender as razões para as meninas não escolherem cursos superiores na área da Computação, foi aplicado questionário e 140 estudantes participaram (79 meninas e 61 meninos), de seis escolas da cidade de Jacobina - BA. Os resultados da pesquisa apontaram que a origem do desinteresse feminino pela área tem como um dos principais fatores a falta de estímulo da família e da escola, por aspectos como a falta de acesso a brinquedos tecnológicos e acesso a recursos financeiros. Também a falta de conhecimento da área é um fator apontado. Dentre as alunas de escola pública, $56,4 \%$ já pensaram em cursar algum curso da área da Computação, esse índice foi de $25 \%$ entre meninas de escolas particulares [10].

Foi realizado um mapeamento com 198 meninas do Ensino Médio de cinco escolas para identificar aspectos a serem contemplados no planejamento de ações para a democratização do saber e atração de meninas para a área da Computação. Foi aplicado questionário e sobre o conhecimento em relação à área de Computação: $12 \%$ indicam saber o que faz um profissional de Computação; $20 \%$ consideram a Computação uma área difícil; $12 \%$ relacionam a área ao público masculino; $60 \%$ acham difícil a inserção do profissional no mercado de trabalho; $87 \%$ indicam que é possível usar a criatividade na Computação; $41 \%$ consideram que na Computação há bons salários. Sobre interesse do público em relação a cursos relacionados com a área de Computação: 69\% não pensam em seguir na Computação e 62\% gostariam de participar de cursos para aprender mais sobre a área [32].

Com o intuito de analisar se a condição financeira das alunas e o apoio da família são determinantes na escolha por um curso na área de Computação, foram entrevistadas/os meninas/os do $3^{\circ}$ ano do Ensino Médio em escolas públicas e privadas em Ouro Branco - MG. A pesquisa foi executada ao longo do ano de 2018. Foram entrevistados 138 estudantes: 41 nas escolas particulares (22 alunas e 19 alunos) e 97 nas escolas públicas (66 alunas e 31 alunos). Nos resultados, sobre a possibilidade de fazer curso na área de Computação: 95\% das alunas de escola particular responderam não; e $65 \%$ das alunas de escola pública responderam não. Podese notar que as meninas de escola pública demonstraram maior interesse pela área que as meninas de escolas particulares [35].

Em [26] o objetivo foi identificar fatores que influenciam de forma positiva e negativa a escolha da Computação, com base na Teoria Sociocognitiva da Carreira (TSCC). No trabalho foram utilizados dados de uma das atividades realizadas em uma pesquisa de doutorado de Ribeiro (2020). Essa atividade faz parte do projeto Meninas Digitais Mato Grosso. Participaram 78 alunas de $1^{\circ}, 2^{\circ}$ e $3^{\circ}$ ano do Ensino Médio Integrado com a Educação Profissional na área de Informática, no Mato Grosso, de escolas estaduais e federais. Os fatores positivos e negativos foram agrupados em: ambientais, comportamentais, biológicos, cognitivos e afetivos. Os fatores positivos mais citados pelas estudantes foram: gostar da área; possuir experiência na área; ter interesse na área; fazer o Ensino Médio Integrado na área da Informática. Os fatores negativos mais citados foram: indecisão; insegurança; dificuldade no curso; instabilidade profissional; cansaço; desmotivação; estresse; incapacidade; arrependimento; falta de interação com as pessoas; sobrecarga; concorrência e falta de reconhecimento social.

Relacionado ao trabalho acima, em [53] com as mesmas estudantes e 2 docentes, Ribeiro e Maciel (2020b) realizaram um estudo sobre o processo de desenvolvimento da carreira de meninas do Ensino Médio integrado a educação profissional (EMIEP) em Informática para identificar fatores que contribuem na continuação da formação em curso superior em Computação. Dentre os fatores de influência alguns apontados foram: Desenvolvimento de 
interesses ao longo do tempo (brincadeiras na infância, tecnologias na infância, hobbies); Escolha pelo EMIEP em Informática (escolha pela escola, escolha pela educação profissional, escolha por informática); Desempenho no EMIEP em Informática (satisfação pessoal, satisfação com a escola, satisfação com o curso, escolha por outra área, escolha por Computação).

Ainda, sobre no contexto de EMIEP, em [39] foi investigado o perfil de estudantes de diferentes níveis de ensino na área de Informática do Instituto Federal de São Paulo (IFSP), de Bragança Paulista, para elaborar estratégias para cursos e projeto de extensão IF(meninas) \{nas exatas\}. Sobre as alunas do Ensino Médio, houve 40 respostas ao questionário aplicado. As principais dificuldades que apontaram foram: disciplinas técnicas, hardware, redes, sistemas operacionais, programação, identificação, tempo, interesse, conceitos, lógica de programação, algoritmos, matemática, termos técnicos, vetor, matriz, Java, Linux. As autoras consideram que são necessárias atividades que contribuam para a organização do tempo, grupos de estudos, oficinas e clubes de programação para trabalhar sobre essas dificuldades.

Foi realizada pesquisa sobre a perspectiva de futuro de alunos/as de duas escolas de Ensino Médio públicas, vinculada ao grupo de extensão Garotas Tech dos Sertões de Crateús, em 2019. Para isso foi aplicado questionário em turmas do $2^{\circ}$ e $3^{\circ}$ anos, com participação de 291 alunos, dos quais 148 do sexo feminino. Em relação às estudantes, 98 têm interesse em entrar na universidade; 12 indicaram saber que existem cursos de TI na Universidade Federal do Ceará (UFC - Crateús); e nenhuma soube descrever a atuação de um profissional de TI. Desse modo, os resultados apontaram para a necessidade de divulgação sobre a área [5].

No estudo de [15] buscou-se saber o nível de informação de alunas do Ensino Médio sobre as subáreas da Computação e o nível de interesse em conhecer mais sobre as mesmas. Participaram 35 alunas, com idades entre 14 e 19 anos, do Instituto Federal de Mato Grosso na cidade de Campus Pontes e Lacerda, durante uma atividade do projeto Meninas Digitais Regional Mato Grosso. O questionário aplicado em abril de 2015, continha as 27 subáreas da Computação. As áreas de maior interesse foram: Inteligência Artificial e Inteligência Computacional (48,6\%), Robótica $(48,6 \%)$ e Jogos e Entretenimento Digital (45,7\%). As subáreas menos interessantes segundo as participantes são: Arquitetura de Computadores, Engenharia de Software e Algoritmos, todas com 28,6\% das respostas. As subáreas mais conhecidas e interessantes foram: Informática na Educação, Linguagens de Programação e Jogos e Entretenimento Digital, todas com 14,3\%.

\section{Iniciativas para atrair meninas para a Computação}

No estudo de [59] foram apresentadas as estratégias adotadas para implementar o Programa Meninas Digitais desenvolvido pela Sociedade Brasileira de Computação. São apresentadas ações de projetos associados ao programa, dentre eles: Emíli@s - Armação em bits; \#include <girls.UFF>; Meninas Digitais Mato Grosso; Garotas Digitais da Bahia; Cunhantã Digital. Em [34] foi apresentada uma proposta de trabalhar com estudantes do Ensino Médio de escolas públicas para mostrar distintas áreas da TI e desenvolver habilidades em programação. As ações estão vinculadas ao Programa Meninas Digitais. Foram planejados alguns cursos (Web, Banco de dados, HTML, Android, Redes etc.) por professores da Escola de Ciência e Tecnologia da UFRN e visita ao Instituto Metrópole Digital para conhecer a infraestrutura de TI em geral.

Nesse mesmo sentido, [14] apresentaram ações do projeto Meninas Digitais Regional Mato Grosso, durante o período de 2015-2016. Foram desenvolvidas atividades motivacionais e informativas com alunas do Ensino Médio. Nas atividades realizadas estão: levantamento e análise de dados da participação feminina no curso de Bacharelado de Sistemas de Informação; produção de materiais gráficos sobre cursos de Computação e afins e sobre temáticas 
relacionadas a mulheres na área; realização de oficinas e palestras; participação de alunas em competições; realização de eventos.

Relacionado a competições, [36] apresentaram a participação do estado do Mato Grosso na competição Technovation Challenge, edição de 2017. O evento é voltado para meninas de 10 a 18 anos, do Ensino Médio e Fundamental. A partir do projeto Meninas Digitais, que funciona no Instituto Federal do Mato Grosso (IFMT), foi incentivada a participação destas meninas na competição, bem como a preparação. No artigo é relatado que estavam participando dez equipes Sênior e uma Júnior com alunas do IFMT de Ensino Médio dos campi de Tangará da Serra e de Campo Novo do Parecis, além de alunas do Ensino Fundamental da cidade Tangará da Serra.

O projeto Meninas Digitais UFSC apresentou atividades realizadas em uma escola pública na cidade de Tubarão em Santa Catarina [3][7][8]. Foram realizadas oficinas para 8 alunas do Ensino Médio, com a duração de três horas sobre conteúdo básico de eletricidade. Foi utilizado nos experimentos o Snap Circuits, um kit educacional para o uso de componentes eletrônicos [3]. Nessa mesma temática, na oficina sobre conceitos de eletricidade, eletrônica e tecnologia, realizada em 2015, foi utilizado o kit didático de eletrônica LittleBits, que contou com a participação de oito estudantes do Ensino Médio [8]. Em [7] foram relatadas 2 oficinas de aplicativos móveis, realizadas em 2014, e participaram 27 estudantes. Foi aplicado o MIT App Inventor como ferramenta para o desenvolvimento de aplicativos. Ao fim das oficinas as meninas demonstraram bastante entusiasmo pelos novos conhecimentos e em ver os aplicativos produzidos por elas mesmas.

Os trabalhos [20] e [58] apresentaram atividades do projeto Meninas.comp. Em [20] foram relatadas atividades realizadas em 2015, em escolas públicas do Distrito Federal. É apresentada a sistemática do projeto e a necessidade de aproximação entre escola e universidade para atrair o interesse e a participação de alunas do Ensino Médio nas atividades do projeto. Foram desenvolvidas atividades sobre robótica, com uso de kits e equipamentos e propostos desafios às alunas com base nas reuniões do projeto realizadas com as estudantes na escola [20]. No trabalho [58], foram realizadas oficinas de desenvolvimento de jogos como Kodu, aplicativos para celular com o MIT App Inventor e de robótica com Arduino. Tais oficinas têm sido desenvolvidas ao longo dos 9 anos do projeto em escolas, na UnB e em eventos no Brasil com meninas estudantes.

Há dois trabalhos vinculados ao projeto Meninas Digitais do Vale [2][16], em [2] foi utilizado o jogo Computasseia, em atividades de cursos de extensão da UFC. Foi realizada atividade com estudantes do Ensino Médio e da graduação, de ambos os sexos. O objetivo do jogo é abordar sobre a História da Computação. As atividades foram avaliadas por meio de questionário. As autoras apontam que o jogo pode contribuir para o reconhecimento das mulheres na área da TI. No trabalho [16], foi realizada uma oficina de programação na plataforma Code.org com estudantes do Ensino Médio, de ambos os sexos, em Russas (CE). Participaram 28 estudantes do $2^{\circ}$ ano e duas estudantes de graduação do projeto conduziram a atividade e auxiliaram os/as estudantes. Foram obtidas respostas de 13 meninas e 15 meninos na avaliação do curso e os resultados sobre a experiência do usuário mostraram que a maioria das meninas se sentiu indiferente quanto à satisfação e atenção focada que o jogo proporcionou.

No estudo de [9] foi relatada a experiência de oficinas de lixo eletrônico, a atividade foi vinculada ao Programa Meninas Digitais e ao projeto parceiro Emíli@s - Armação em bits. Participaram 28 estudantes (12 meninas e 16 meninos) do $1^{\circ}$ ano do Curso Técnico em Informática Integrado ao Ensino Médio do Instituto Federal do Paraná (IFPR). A oficina foi proposta com a disciplina de Artes I, de modo interdisciplinar. Foram realizados 3 encontros entre o final de maio e início de junho de 2019 no horário das aulas. Os/As autores/as apontam que as oficinas permitiram a realização de uma atividade interdisciplinar que incentiva o ensino 
da Computação, estimula o pensamento crítico, permitiu conhecer mulheres da área e contempla o eixo de Tecnologia e Sociedade.

Em [21] foram apresentados resultados iniciais do projeto Meninas Paid'éguas, vinculado ao Programa Meninas Digitais, desde 2019, com objetivo de despertarem o interesse de meninas de Ensino Médio pela Computação. Foram realizadas palestras e oficinas e utilizados recursos digitais como o stop motion, usando o PIC-PAC stop motion, para a construção de animações, desenvolvendo competências e habilidades por meio de recursos tecnológicos. Das 35 meninas que participaram de alguma das oficinas: 25 consideraram excelente, 8 consideraram muito bom e 1 como bom. Numa perspectiva mais abrangente, em [63] foi apresentado o projeto Cunhantã ++ que tem o objetivo de ensinar robótica em escolas desde o jardim de infância ao Ensino Médio/Técnico para aumentar o interesse pela matemática e lógica. $\mathrm{O}$ foco é aproximar o público feminino amazônico e para isso são desenvolvidos exposições, competições e cursos de programação e Arduino, com Scratch, Python e C.

O projeto de extensão Maria Bonita nas Ciências realizou atividades de agosto a novembro de 2019, totalizando 13 encontros, em 3 escolas públicas no Rio Grande do Norte. As atividades iniciaram com 30 alunas, mas somente 20 terminaram o curso. Foram realizadas oficinas, cursos, filmes, mesa-redonda e palestras temáticas e no questionário avaliativo do curso: $68 \%$ das meninas amaram o projeto; $84 \%$ indicariam com certeza para outras meninas; $84 \%$ das meninas demonstraram interesse em trabalhar na área [6].

No projeto Meninas Digitais Tchê Missões foram realizadas atividades com 54 estudantes do Ensino Médio de escolas públicas e privadas em Santo Ângelo do Rio Grande do Sul. Foi desenvolvido um curso de aulas de programação em Android, através da plataforma App Inventor, com oito semanas de duração. A partir disso, foram construídos aplicativos e realizado um desafio. Foi observado o interesse das meninas nas atividades do projeto, bem como foi o primeiro que participaram para conhecer mais sobre a área [33].

Através do projeto Trazendo Meninas para Computação, foram realizadas atividades com quinze alunas do Ensino Médio em Picada Café - RS, durante o ano de 2014. Aconteceram seis oficinas quinzenais ministradas por professoras da área de Computação sobre raciocínio lógico, programação, desenvolvimento de páginas web, robótica e desenvolvimento de projetos. Foram utilizadas ferramentas como: MovieMaker, Scratch, HTML e kits LEGO. Também foram realizadas visitas a uma empresa de desenvolvimento de software e a universidade [27].

No projeto Android Smart Girls participaram estudantes do $1^{\circ}$ ao $3^{\circ}$ ano do Ensino Médio, em 2014. Foi realizada uma palestra sobre o projeto e também um curso para desenvolvimento de aplicativos móveis utilizando o App Inventor, o qual contou com aplicação de questionários avaliativos no início e no final do mesmo. Incialmente, 22 alunas participaram e encerrou com 9 concluintes. As participantes se consideravam boas alunas, recebiam apoio familiar e tinham uma visão pouco clara sobre Computação. Ao fim do curso, as autoras perceberam que as alunas compreendiam melhor a profissão de Engenharia e Ciência da Computação [44].

No projeto Desafio de Programação para Meninas, que foi composto por palestras, oficinas, cursos, ateliers, competição, as atividades foram realizadas no espaço da universidade e participaram 54 meninas. O curso de programação utilizando o App Inventor durou 8 semanas, com carga horária de 32 horas/aula. Foram promovidas oficinas de pitch, brainstorming e utilização de Canvas para elucidação de ideias. Paralelo ao curso foi promovido o atelier de programação para explorar e trocar ideias sobre programação. Por fim, foi realizada uma competição com a formação de equipes para desenvolvimento de aplicativos [50].

O projeto Meninas, Computação e Música foi desenvolvido com o objetivo de atrair meninas para cursos de Computação. Foram selecionadas quatro meninas do ensino público e tiveram aulas de música e de programação em Java de professores dessas áreas, com duração de 
duas vezes por semana, por quatro horas diárias. Também foi utilizado o Greenfoot, o ambiente de desenvolvimento de jogos. Foram criados jogos para instrumentos musicais (bateria, contrabaixo, guitarra, teclado). Inicialmente, os cursos foram vistos como complexos pela presença da programação. Ao final, as alunas notaram que programação não era tão difícil, ficaram motivadas com o resultado final do projeto. Ainda, houve alunas que consideraram escolher cursos da área no vestibular [17].

Os trabalhos de [22] e [31] desenvolveram atividades em uma mesma escola de Ensino Médio pública. Em [31] foi realizado um curso com duração de dois meses (maio a julho de 2014) para meninas, através da Universidade Federal de Santa Catarina, em Sombrio-SC. Participaram trinta meninas e foram trabalhados conteúdos como lógica computacional, montagem e programação de um kit robótico, desenvolvimento de pseudocódigos no ambiente de programação VisualG. No trabalho de [22] foi desenvolvido um projeto sobre ensino de física e matemática com auxílio da robótica. O curso foi realizado entre dezembro de 2014 e março de 2015, durante três meses, participaram quinze meninas e foi utilizado o kit LEGO. Em ambos os trabalhos, notou-se maior motivação entre as estudantes após o curso.

Em atividades de um projeto de extensão, a linguagem de programação Scratch foi utilizada para aumentar o interesse de meninas do Ensino Médio. O curso teve duração de 10 horas, com aulas de 2 horas e contou com a participação de 3 alunas. Foram utilizados conhecimentos de matemática, física e química para a construção de animações. Os resultados mostraram interesse das meninas pela experiência e o estímulo ao desenvolvimento do Pensamento Computacional. Uma das alunas apontou a Computação como uma opção de curso [46].

Em [38] foram descritas oficinas realizadas com alunas do $1^{\circ}$ ano do Ensino Médio de uma escola pública do Distrito Federal, em 2017. A iniciativa surgiu a partir da demanda da escola e da proposta de duas alunas para a disciplina de Teoria e Prática Pedagógica em Informática 1, do curso de Licenciatura em Computação da Universidade de Brasília - UnB. Foram realizadas oficinas de Arduino, uma vez por semana, no turno da tarde, durante 7 encontros no semestre 2017/2, que contou com a participação de 17 estudantes. Para despertar o interesse das estudantes foi criada a oficina "Mulheres de Ferro". Na avaliação final das oficinas, as alunas relataram ter aprendido mais sobre informática e demonstraram interesse pela possibilidade de ingressar na área.

O trabalho de [28] compartilhou as experiências do Technovation HackDay, em 2018, realizado no Instituto de Ciências Matemáticas e de Computação (ICMC) da Universidade de São Paulo (USP), para meninas entre 10 e 18 anos. O objetivo foi apresentar carreiras da área de computação e empreendedorismo, as palestras foram realizadas apenas por mulheres e também foi realizada oficina utilizando o App Inventor. Participaram 74 alunas e foram confeccionados 13 aplicativos diferentes. As alunas receberam auxílio de alunos e profissionais de áreas de exatas e tecnologia. $\mathrm{O}$ evento também inspirou a criação do Grupo de Alunas nas Ciências Exatas (GRACE) no ICMC/USP, para promover carreiras de TI para alunas do Ensino Fundamental e Médio.

Ainda, em [37] foi investigado o quanto competições de programação voltadas para meninas do Ensino Médio/Técnico influenciam na motivação para que participem desses eventos. Essa atividade foi vinculada ao programa de extensão MinasCoders, da Universidade Federal de Viçosa/Florestas. Foram analisados dados referentes à participação de meninas do Ensino Médio/Técnico em 4 competições de programação no triênio 2017-2019 (duas de programação e 2 de empreendedorismo e tecnologia). O incentivo nas atividades ao longo dos anos gerou um aumento na participação das meninas nas competições. Foi observado que as competições tradicionais de programação não parecem atrair o interesse desse público. As competições de empreendedorismo e tecnologia que utilizam propostas mais lúdicas e aplicadas na realidade atraem mais o interesse das meninas. 
Para incentivar a participação nas competições, no projeto de ensino de robótica e aprendizagem criativa, denominado projeto Metabotix, as estudantes são desafiadas a construir pequenos robôs e também a participarem de eventos de robótica. Desde 2016 é realizado um projeto de ensino voltado para a Olimpíada Brasileira de Robótica (OBR) e ao longo dos anos teve um aumento na participação de estudantes do Instituto Federal de Goiás (IFG) na OBR a partir das atividades do projeto e também de alunas interessadas em competir [30]. Relacionado à robótica, foi executado um projeto na Universidade Regional Integrada do Alto Uruguai e das Missões (URI) e contou com a participação de 71 meninas, do $1^{\circ}$ ao $3^{\circ}$ ano do Ensino Médio. Foi realizada uma competição entre equipes para a criação de robôs personalizados. Esta experiência possibilitou que as meninas vivenciassem atividades de Computação de forma atrativa e despertaram o interesse pela área. Além de apontar para possibilidade de utilizar em conteúdos de formação básica, como matemática e física, práticas que envolvem robótica [49].

Nesse mesmo sentido, em [42] foram realizadas oficinas de robótica através do projeto Mulheres na Ciência da Computação: Despertando vocações através da difusão do conhecimento. As participantes foram 8 alunas (do $1^{\circ}$ ao $3^{\circ}$ ano) de escola pública, em João Pessoa - PB. Houve cinco encontros durante aproximadamente 3 meses e foram utilizados kits ROBO TX Explorer. Foi aplicado questionário antes das oficinas para detectar conhecimentos de robótica e programação. Uma das alunas já havia montado um robô e achou fácil. Ao fim das oficinas as meninas se mostraram mais interessadas na área da Computação.

O projeto Meninas na Ciência, da Universidade Federal do Rio Grande do Sul, que busca atrair meninas para carreiras de Ciência e Tecnologia, com atividades relacionadas à Física, Robótica e Astronomia, também tem o intuito de sensibilizar a comunidade acadêmica e comunidade externa sobre o papel da mulher na sociedade, visando eliminar estereótipos de gênero. Meninas e meninos do Ensino Médio e Fundamental de escola pública participaram das atividades. Foram realizadas visitas à universidade, debates e discussões mediadas por filmes, oficinas, feira, produção de vídeos [54].

Em [61] foi examinada a aplicabilidade da robótica para ensino de disciplinas de Science, Technology, Engineering, Arts e Mathematics (STEAM) e princípios de programação em escolas públicas. Participaram 22 estudantes (6 meninas e 16 meninos), dentre as 6 meninas, 3 afirmaram se sentir mais à vontade com tutoras nas aulas. Foram organizadas equipes mistas para a interação entre ambos os sexos. Ao analisar potenciais diferenças entre os gêneros, em relação à participação em sala de aula as meninas foram menos ativas. Conforme o cenário analisado, esse aspecto possivelmente era devido à maioria de homens na classe.

No trabalho de [47] foi relatada uma experiência de ensino de lógica de programação em uma abordagem construtivista, na qual participaram 22 meninas de $1^{\circ}$ ao $3^{\circ}$ ano do Ensino Médio, no Pará. Foram desenvolvidas 8 aulas, a primeira aula foi uma palestra e nas aulas seguintes foi para programação de um jogo sobre mulheres na Computação. Observou-se que $75 \%$ se sentiram muito motivadas. Sobre a aprendizagem, 45\% consideraram ótimo; $45 \%$ consideraram bom e 10\% consideraram neutro. Ao fim do curso, dentre as 20 alunas que finalizaram $65 \%$ demonstraram muito interesse por estudar em cursos de Computação. No início $19 \%$ demonstravam muito interesse, isso mostra a contribuição positiva das atividades na visão das alunas sobre a área.

Em pesquisa realizada nos anos de 2016 e 2017 em duas escolas estaduais na Paraíba, a partir um projeto de extensão universitária, foi aplicado questionário e participaram 74 alunas. Os resultados mostraram que $10 \%$ das participantes tinham algum conhecimento sobre programação; $90,9 \%$ tinham expectativa de o curso ser muito difícil; $80 \%$ tinham computador em casa. Ao término do projeto, alunas consideram a possibilidade de escolherem profissões da área. Foram realizadas palestras e debates para difundir experiências de mulheres na área e 
oficinas para o desenvolvimento de aplicativos utilizando Lightbot, Code.org, Scratch e MIT App Inventor [24].

Os trabalhos [23] e [41] desenvolveram atividades em João Pessoa - PB, em escolas públicas diferentes. Em [41] foram apresentadas atividades de um projeto de extensão com meninas do $1^{\circ}$ ano do Ensino Médio e realizadas oficinas de programação no período 20152017. Os encontros ocorreram quinzenalmente, de maio a dezembro, com duração de aproximadamente 4 horas. Ao longo de 3 anos, 18 alunas participaram do projeto. No trabalho de [23] foram apresentadas as iniciativas desenvolvidas com 25 alunas do $1^{\circ}$ ano do Ensino Médio no período de agosto a novembro de 2019. Foram realizadas atividades quinzenais e trabalhados conteúdos sobre lógica de programação. O laboratório da escola estava em reforma e as atividades utilizaram Computação Desplugada, com jogos e identificação de padrões. Ainda, duas oficinas foram realizadas no laboratório, do Centro de Informática da Universidade Federal da Paraíba (UFPB), para desenvolver um aplicativo com o App Inventor e também exploraram ferramentas como Scratch, Lightbot e Code.org.

No estudo de [43] foi relatada a realização de uma gincana envolvendo Computação Plugada e Desplugada, que ocorreu em dois dias em escolas diferentes, realizada através do projeto de extensão do PETComp. As atividades foram organizadas por alunas do curso de Ciência da Computação da Universidade Federal do Maranhão. Para avaliar as atividades, foi aplicado questionário e 30 alunas responderam o instrumento. Observou-se que as alunas da primeira escola preferiram as atividades desplugadas e as alunas da segunda escola preferiram as atividades com o Scratch e, de modo geral, mostraram-se interessadas pela área.

Em [45] foi relatada uma oficina de Banco de Dados utilizando Computação Desplugada como parte da Escola Regional de Banco de Dados, evento que ocorre anualmente de maneira itinerante e contou com a participação de 43 meninas do $2^{\circ}$ e $3^{\circ}$ ano do Ensino Médio, em Chapecó - Santa Catarina. Através do questionário, pode-se notar que a maioria apresentava uma visão limitada sobre profissionais de Computação, relacionada à pessoa que "mexe com computador". Após a oficina declararam uma mudança de percepção, através de falas como: “ "Não é como eu pensava", "Eu achava que era algo chato e não é", "Eu achava que eles ficavam trabalhando somente no computador, mas eles trabalham também com pessoas" "(Berardi et al., 2019, p. 353).

No trabalho de [11] foram compartilhados os resultados da realização do "I Fórum Gurias na Computação: experiências que inspiram", uma ação vinculada ao programa de extensão "GEInfoEdu - Grupo de Estudos na Informática na Educação", realizado em 2015, no Campus Alegrete da Unipampa. A experiência permitiu que os/as participantes (estudantes dos cursos de Ciência da Computação, de Engenharia de Software e de Ensino Médio) do fórum conhecessem a área da TI, dialogassem com mulheres que atuam na área, percebessem a necessidade de estratégias de divulgação e falassem sobre estereótipos e preconceitos. A partir dessa experiência, um dos desdobramentos foi a proposta de uma ação de extensão também denominada Gurias na Computação.

No trabalho de [4] foi apresentado pela ação de extensão citada acima, Gurias na Computação, o planejamento e a execução de uma oficina de 3 horas para estudantes do Ensino Médio do $1^{\circ}$ ao $3^{\circ}$ ano, em 2018, que se realizou com a participação de 12 meninas, das quais 41,7\% afirmaram interesse em cursos da área da Computação. O conteúdo das oficinas foi sobre cursos da área da Computação, aspectos sobre Computação, mulheres protagonistas e experimentação utilizando Computação Desplugada e programação em blocos. Foram obtidos retornos positivos quanto à oficina.

Em [52] foram realizadas visitas a UFPB, palestras, mostra de filmes e oficinas de Computação Desplugada. As oficinas foram a forma de introduzir os conceitos de Computação 
para as alunas que nunca tinham se aproximado da área e estimularam a criatividade, a aplicação da lógica, o trabalho em equipe e a liderança. Também aplicando diferentes estratégias, em [51] foi descrito um conjunto de oficinas realizadas para alunas do Ensino Médio como parte de um projeto de extensão, que contou com a participação de 30 alunas, e realizadas em laboratórios de informática com duração de aproximadamente 3 horas. Foram executadas oficinas de podcasts, construção de páginas web, robótica (kit Lego Mindstorms) e desenvolvimento de jogos (Kodu).

Em uma área mais específica da Computação, [40] descreveu uma experiência de ensino de métodos de avaliação da Engenharia Semiótica para alunas do $1^{\circ}$ ano do Ensino Médio, para que conhecessem sobre a disciplina de Interação Humano-Computador (IHC), em Guarapuava - PR. Foram realizados 4 encontros e quantidade de participantes variada ao longo dos mesmos. Notou-se que as meninas se sentiram mais a vontade sem a presença de meninos. Ao final dos encontros participantes relataram aprender coisas interessantes, sentimento de empoderamento e o despertar do interesse pela Computação.

No trabalho de [48] foram desenvolvidas atividades para atrair meninas para a área de Tecnologia da Informação como realização de palestras, minicurso de HTML e CSS e dinâmicas, em 2014, em Rio Paranaíba - MG. Foi aplicado questionário antes das atividades com 82 estudantes do $3^{\circ}$ ano do Ensino Médio, apenas seis alunas demonstraram interesse pela área de exatas e nenhuma pretendia fazer graduação em Computação/TI. As atividades enfatizaram o público feminino, mas contou a participação de meninos e meninas nas atividades. Nos últimos encontros foi observado que algumas alunas revelaram interesse em saber mais e mudaram um pouco de visão sobre a área.

Nesse mesmo sentido, em [62] foi apresentado o projeto Encorajando Meninas em Ciência, Engenharia e Tecnologia da Informação, parceria entre a Universidade de Caxias do Sul e escolas de ensino fundamental e médio da região. O projeto tinha como objetivo promover: cursos de educação continuada para professores, oficinas, feiras de ciência e tecnologia, olimpíadas, fóruns, dentre outros. Foram apresentados resultados parciais através do desenvolvimento de 5 oficinas que abrangeram aproximadamente 500 meninas, criação de clube de Ciência e Astronomia, feira científica e tecnológica na universidade voltada para as escolas parceiras do projeto.

Evidenciando questões de gênero na área, em [29] foram apresentadas atividades de empoderamento feminino por meio de um projeto de extensão para incentivar a participação de estudantes de cursos de Ensino Médio, Técnico e Superior a permanecerem na área da Computação, foram discutidas questões de gênero e feminismo. As atividades do projeto foram: eventos (debates, mesas redondas, palestras, mostras de filmes), painéis, murais, oficinas, workshops, visitas técnicas, catalogação de materiais (vídeos, fanzines, aplicativos, etc), criação de coletivo de estudos e ações.

Por fim, em [56] foi apresentado um relato de experiência de um projeto de ensino desenvolvido na disciplina de Sociologia com estudantes do Curso Técnico em Informática Integrado ao Ensino Médio, do IFRS - Campus Feliz, no qual participaram 34 estudantes do $2^{\circ}$ ano (10 meninas e 24 meninos). Foram realizadas discussões teóricas sobre conceito de gênero, desigualdades de gênero e mulheres na ciência e tecnologia. Também foi proposta a realização de entrevistas com mulheres profissionais da área e a produção material audiovisual para uma exposição sobre o tema. Ao buscar realizar entrevistas os/as estudantes perceberam dificuldades em encontrar mulheres atuando na região e também entrevistaram alunas do campus que já tinham realizado estágio obrigatório. 


\section{Discussões}

Com base nas questões de pesquisa foi realizada a análise dos artigos selecionados. As subseções a seguir buscam responder as questões levantadas.

\subsection{Fatores apontados para a menor presença feminina na área de Computação}

Em suma, os mapeamentos e levantamentos sobre o interesse de alunas do Ensino Médio apresentados permitem uma visão ampla sobre fatores que interferem e desmotivam a escolha pela Computação. Nota-se que há aspectos fortemente atrelados à visão social construída sobre a área como masculina e com pouca representatividade feminina. Por isso, modificar paulatinamente essa visão é um desafio necessário para que as meninas e jovens se sintam motivadas a fazer cursos e exercer profissões na área.

Nesse sentido, alguns artigos apontam a intimidação de meninas por achar a Computação uma área masculina (Aires et al., 2018; Holanda, Walter, et al., 2017; Moura et al., 2018; Moreira et al., 2019; Santana et al., 2017). Também há posicionamentos das meninas considerando que a mesma não é apenas masculina (Ferreira \& Dias, 2019; Moreira et al., 2019) indicando mudanças de visão e considerando que as mulheres também podem ocupar profissões na área. Ainda, aponta-se para a baixa representatividade de mulheres e como isso é sentido pelas meninas (Ferreira \& Dias, 2019; Moura et al., 2018; Petró et al., 2020; Santana et al., 2017). Por isso, é importante dialogar com outras mulheres que são profissionais ou estudantes, como forma de mostrar as possibilidades das meninas e jovens estudantes futuramente se interessarem na área como escolha profissional (Ferrão \& Melo, 2016; Manentti et al., 2016; Petró et al., 2020; Ribeiro et al., 2016; Santos et al., 2016; Soares et al., 2018). Abordar sobre a história das mulheres na Computação mostra-se fundamental para que as meninas conheçam as contribuições femininas que foram realizadas (Alencar et al., 2019; Amin et al., 2019; Brito et al., 2015; Cruz et al., 2020).

O pouco incentivo da família ou falta de estímulos na infância (por exemplo, brinquedos ou brincadeiras relacionadas à tecnologia) ou escola são fatores que contribuem para as meninas não optarem por áreas da Computação (Deus et al., 2020; Mota \& Adamatti, 2015; Nakamura et al., 2017; Soares et al., 2018; Ribeiro \& Maciel, 2020b). De modo que, aponta-se a necessidade de apoio da família (Holanda, Mourão, et al., 2017; Holanda, Mourao, et al., 2020), bem como de amigos/as e professores/as.

A falta de divulgação sobre a Computação, percepção da área como complexa e diretamente relacionada com a matemática são aspectos apontados que influenciam na escolha profissional. Há uma visão pouco clara sobre o que é realizado em profissões da Computação (Berardi et al., 2019; Deus et al., 2020; Figueiredo et al., 2017; Grings et al., 2018; Ramos et al., 2015; Santos, Santos, et al. 2017; Santos, Silva et al., 2017). Também há meninas que não acreditam ter habilidades suficientes para a área, devido a estereótipos socialmente construídos (Nakamura et al., 2017) e de não ter afinidade com Matemática (Ferreira e Dias, 2019; Nakamura et al., 2017; Sidnei et al., 2020).

Mesmo quando gostam de disciplinas de Exatas no Ensino Médio, preferem profissões de outras áreas como Ciências Biológicas, Ciências da Saúde ou Ciências Humanas (Grings et al., 2018; Nakamura et al., 2017; Ribeiro \& Maciel, 2020a; Santos, Silva, Silveira, et al., 2017). Quando questionadas se gostariam de seguir na Computação há baixos índices de interesse (Holanda, Mourao, et al., 2020; Nunes et al., 2015; Santos, Santos, et al., 2017; Sidnei et al., 2020). Por isso, as iniciativas de atividades e projetos para as meninas necessitam integrá-las e familiarizá-las (Andrade et al., 2020; Berardi et al., 2019; Frigo et al., 2013), bem como aumentar o interesse pelas Exatas (Brito et al., 2015; Gomes et al., 2014; Manentti et al., 2016; Moreira et al., 2019; Sauer et al., 2020; Sousa et al., 2020). Desse modo, é preciso compreender 
e agir sobre os fatores que afastam as meninas desse campo do conhecimento. Mesmo as que já estão no Ensino Médio Técnico apresentam baixos índices de escolha pela área para seguir no Ensino Superior (Ribeiro \& Maciel, 2020a, 2020b).

Ter um panorama sobre fatores que afastam as meninas das áreas da Computação permite subsidiar a construção de iniciativas para atrair meninas e jovens mulheres, apresentar as diversas áreas da Computação, fortalecer o ensino de disciplinas de Exatas no Ensino Básico, disseminar atividades que abordam sobre Pensamento Computacional e reduzir os estereótipos sobre as profissões. Dessa forma, contribuir para uma sociedade mais justa e menos preconceituosa em relação às mulheres.

\subsection{Iniciativas para atrair meninas para cursos de áreas da Computação}

Os trabalhos apresentam um cenário diversificado quanto às estratégias e metodologias que são aplicadas nas atividades. Destaca-se o uso de oficinas e palestras, principalmente oficinas sobre produção de aplicativos com ferramentas como App Inventor e Scratch, as quais buscam introduzir as alunas na área da Computação de modo lúdico e sem exigir níveis avançados na programação para que isso não seja um fator que gere frustração no contato inicial. Mattos et al. (2016) ao analisar o uso do Scratch apontam que utilizar apenas uma abordagem de estímulo não é suficiente, por isso a necessidade de estudos que explorem outras abordagens. Os projetos com maior duração auxiliam no aprendizado sistemático e maior contato com a universidade e as alunas do Ensino Médio. A maioria dos trabalhos analisados utilizou questionários para avaliar as atividades realizadas e ter um feedback das participantes.

Diversos trabalhos mostram que atividades relacionadas à programação podem despertar o interesse e entusiasmo para conhecer sobre a área e em alguns casos considerar como uma escolha de curso. Desse modo, contribuir para a familiarização com a Computação (Almeida et al., 2016; Berardi et al., 2019; Bim, 2011; Campos \& Melo, 2020; Cardoso et al., 2016; Coelho et al., 2016; Gimenez et al., 2016; Grings et al., 2018; Gomes et al., 2014; Lima et al., 2020; Manentti et al., 2016; Matos et al., 2019; Mattos et al., 2015; Nunes et al., 2015; Pinto et al., 2020; Pontes et al., 2019; Ramos et al., 2015; Ribeiro et al., 2016; Santos et al., 2016; Santos et al., 2019; Santos, Silva et al., 2017; Santos, Silva, Silveira, et al., 2017; Soares et al., 2018). Contudo, há a necessidade de iniciativas em longo prazo para observar se o interesse na Computação foi mantido nas participantes, bem como incentivar a participação em outras atividades da área de modo contínuo.

Ainda, a Computação Desplugada está presente como estratégia para desenvolver o Pensamento Computacional e realizar atividades e brincadeiras mesmo sem o computador, aumentando também o leque de possibilidades de atividades (Amib et al., 2019; Berardi et al., 2019; Mattos et al., 2020; Pinto et al., 2020; Pontes et al., 2019). Há estudos que mostram problemas de infraestrutura nas escolas e como isso também interfere negativamente nas atividades (Fiori et al. 2019; Mattos et al. 2020; Ramos et al., 2015). Esse aspecto precisa ser levado em conta ao organizar e propor as atividades nos projetos e compreender a realidade das escolas públicas do Brasil, onde ainda há a carência de laboratórios de Informática.

As discussões sobre questões de gênero e as mulheres na Computação também podem dar base para as estudantes terem uma formação político-filosófica para que questionem sobre os preconceitos, transformem a realidade em que estão inseridas e quebrem estereótipos (Brito et al., 2015; Ferrão \& Melo, 2016; Petró et al., 2020; Santana et al., 2017). Também aponta a necessidade da universidade fomentar pesquisas sobre gênero na educação e no mercado. Tais pesquisas podem contribuir para o desenvolvimento da sociedade (Figueiredo \& Maciel, 2016). Levantamentos em longo prazo mostram que o interesse pela área não tem aumentado significativamente e iniciativas que possam abranger o Ensino Fundamental podem ser mais efetivas que no Ensino Médio, fase na qual as meninas já têm escolhas profissionais mais 
definidas (Grings et al., 2018; Holanda, Mourão, et al.; 2017; Holanda, Mourao, et al., 2020; Holanda, Walter, et al., 2017).

Além disso, esta RSL permite identificar quais projetos estão à frente das atividades e permite identificar a rede de pesquisadores que atuam nessas iniciativas. Dentre eles, há uma quantidade significativa de projetos parceiros do Programa Meninas Digitais da Sociedade Brasileira de Computação (SBC) (Maciel et al., 2018). Ainda, os projetos apresentados nos trabalhos analisados estão fortemente relacionados com a universidade e iniciativas para aproximar o Ensino Superior do Ensino Fundamental e Médio. A troca de saberes entre universidade e comunidade externa mostra-se uma forma promissora de integrar as meninas do entorno e regiões próximas ao conhecimento acadêmico produzido. Além de despertar o interesse para seguir em profissões que até então podiam ser desconhecidas ou pouco claras para as estudantes. "Assim, uma maior integração entre a Universidade e as escolas de ensino médio poderia ajudar a diminuir o agudo problema da falta de profissionais mulheres nas áreas de Computação" (Holanda, Walter, et al., 2017). Para aumentar o interesse das meninas, elas podem ser motivadas por outras meninas e mulheres; promover explicações claras sobre as áreas de Exatas; criar ações sistematizadas que levem em conta a realidade local; dentre outros aspectos que podem direcionar nas estratégias a serem adotadas para atrair meninas para a Computação (Santos, Santos, et al., 2017).

Assim, ressalta-se que visualizar as ferramentas, metodologias e estratégias dos estudos fornece subsídios para que pesquisadores/as e docentes da Computação possam refletir sobre a construção e implementação de novas iniciativas para atrair meninas para a área e fazer parcerias com a Educação Básica.

\section{Considerações Finais}

A presença das mulheres na área da TI nos diferentes cursos de Computação precisa ser constantemente motivada. Mesmo com avanços em relação à formação acadêmica, entrada na universidade e inserção no mercado de trabalho, ainda há uma série de desafios a serem enfrentados para que as mulheres continuem na consolidação de espaços de atuação. Esse processo pode ser visto nas escolhas profissionais das meninas a partir do Ensino Básico. De modo que, a atuação sobre o ensino de Computação nesse nível de ensino pode refletir nas futuras escolhas de cursos técnicos e superiores das meninas e jovens.

De modo geral, os trabalhos presentes nesta RSL apresentam o objetivo de despertar o interesse de meninas e jovens do Ensino Médio pela Computação. Nos diferentes níveis de formação, seja Técnico ou Superior há estudos que evidenciam que as mulheres ainda buscam figuras de referência para se sentirem representadas e inspiradas a exercerem profissões dessa área. Projetos que incentivam a parceria entre universidade e escolas são possibilidades que contribuem para esclarecer dúvidas sobre áreas tecnológicas, em específico sobre a Computação. Isso também fortalece a inserção da Computação na Educação Básica, consequentemente promovendo a desmistificação dessa área para as meninas, de modo a contribuir para o interesse e a escolha de cursos da área.

Sobre as regiões, a maioria dos estudos é da região Sul e Centro-Oeste. Os estados com maior representação são Rio Grande do Sul, Mato Grosso, Paraíba e Santa Catarina. Destaca-se que tais publicações decorrem de ações referentes principalmente a projetos de extensão vinculados a SBC. Destacaram-se as oficinas e palestras como forma de trabalhar com as alunas. $\mathrm{O}$ ano com mais publicações foi 2020. Nas atividades de cursos e oficinas a presença de universitárias de cursos da área foi também um modo de incentivar as mesmas a vivenciarem experiências que as atraíssem para a prática profissional. Outro aspecto é sobre a infraestrutura para desenvolvimento das atividades, onde a maioria das atividades ocorreu nas dependências da 
universidade proponente, pois as escolas públicas em sua maioria não têm laboratórios de Informática ou quando têm os mesmos apresentam limitações que comprometem o andamento das práticas. Por isso, o financiamento de projetos é fundamental para que as atividades possam se desenvolver e para comprar equipamentos.

Sobre a QP1, relativa aos fatores apontados para a menor presença de meninas em cursos de Computação, os estudos mostraram que ainda há uma percepção da área como masculinizada, receio quanto às dificuldades em disciplinas matemáticas, subestimação sobre o trabalho que a mulher pode realizar em relação ao do homem, desconhecimento sobre as profissões relacionadas à área da Computação, falta de apoio familiar e de colegas. Esses fatores refletem aspectos estruturais da sociedade e requerem iniciativas que intervenham sobre a realidade social, com o intuito de promover equidade.

Sobre a QP2, relacionada às iniciativas para atrair meninas para cursos da área da Computação, os estudos apresentam uma variedade de possibilidades que podem ser trabalhadas com estudantes do Ensino Médio, as quais visam inserir o Pensamento Computacional por meio de atividades práticas. Os projetos partem em sua maioria de iniciativas de institutos e universidades públicas e que também focam nas alunas de escolas públicas. Esse aspecto evidencia o papel de retorno à comunidade do conhecimento produzido nessas instituições, bem como o reconhecimento da precariedade das condições do ensino público que também influencia na formação das alunas. Esse aspecto também se relaciona ao ensino de disciplinas de Exatas no Ensino Básico que pode ser precário e não faz com que as alunas se sintam preparadas para escolherem profissões da Computação. Ainda, as atividades identificadas contribuem também para o nível superior, pois buscam envolver alunas da graduação em projetos e as mesmas podem vivenciar as possibilidades de atuação na área.

Assim, este trabalho espera contribuir para a visualização de um panorama das atividades realizadas no intuito de promover a inserção de alunas do Ensino Médio na Computação, apontando ferramentas, estratégias e resultados que podem ser base para estudos futuros e replicações em escolas brasileiras. Além disso, mostra que há uma necessidade de continuidade dos projetos para que a partir da extensão os mesmos possam a cada ano consolidar a parceria entre escolas, institutos e universidades e popularizar a Computação como área de atuação para as mulheres na nossa sociedade. Sobre as limitações deste trabalho, esta revisão sistemática foca especificamente no contexto do Ensino Médio no Brasil, ainda outros indexadores de busca relacionados à temática podem expandir novas buscas. Para trabalhos futuros, essa investigação pode ser realizada quanto aos demais níveis de ensino, de modo a avançar em estudos que permitam compreender uma visão macro sobre as mulheres na Computação no Brasil.

\section{Agradecimentos}

Ao Instituto Federal de Alagoas (IFAL), pelo apoio à qualificação profissional para realização do Doutorado em Educação da primeira autora. À Josineise Maria de Oliveira Menezes, pela contribuição na revisão ortográfica deste trabalho.

\section{Referências}

Abbate, J. (2003). Women and gender in the history of computing. In: IEEE Annals of the History of Computing. IEEE Computer Society. [GS Search]

Amaral, M. A., Emer, M. C. F. P., Bim, S. A., Setti, M. G., \& Gonçalves, M. M. (2017). Investigando questões de gênero em um curso da área de computação, Estudos Feministas, 
Florianópolis, 25 (2), 857-874, mai./ago. DOI: 10.1590/1806-9584.2017v25n2p857 [GS Search]

BBC. (2019). Como algoritmo criado por jovem cientista possibilitou a $1^{\text {a }}$ foto de buraco negro. Recuperado de https://www.bbc.com/portuguese/geral-47886045. Acesso em: fevereiro de 2021.

Cesario, G., Silveira, N. G., Bim, S. A., \& Maciel, C. (2017). Por Mais Mulheres na Computação: análise dos trabalhos publicados no X Women in Information Technology. In: Anais do XI Women in Information Technology. Porto Alegre: SBC. DOI: 10.5753/wit.2017.3409 [GS Search]

Cisne, M. (2015). Gênero, divisão sexual do trabalho e serviço social. 2 ed. São Paulo: Outras Expressões.

Figueiredo, K. S., \& Maciel, C. (2016). Reflexões sobre gêneros, tecnologia e processo vocacional. In: Anais do XIII Women in Information Technology (WIT 2016). XXXVI Congresso da Sociedade Brasileira de Computação (CSBC 2016), p. 2728-2731. DOI: 10.5753/wit.2016.9709 [GS Search]

Fonseca Filho, C. (2007). História da computação: o caminho do pensamento e da tecnologia. Porto Alegre: EDIPUCRS.

Grossi, M. G. R, Borja, S. D. B., Lopes, A. M., \& Andalécio, A. M. L. (2016). As mulheres praticando ciência no Brasil. Revista Estudos Feministas, 24(1), p. 11-30. DOI: 10.1590/18059584-2016v24n1p11 [GS Search]

IBGE. (2019). Instituto Brasileiro de Geografia e Estatística. Agência IBGE Notícias. Em média, mulheres dedicam 10,4 horas por semana a mais que os homens aos afazeres domésticos ou ao cuidado de pessoas. Recuperado de https://agenciadenoticias.ibge.gov.br/agencia-sala-deimprensa/2013-agencia-de-noticias/releases/27877-em-media-mulheres-dedicam-10-4-horaspor-semana-a-mais-que-os-homens-aos-afazeres-domesticos-ou-ao-cuidado-de-pessoas. Acesso em: fevereiro de 2021.

IBGE. (2016). Instituto Brasileiro de Geografia e Estatística. Estatísticas de gênero: indicadores sociais das mulheres no Brasil. Recuperado de https://www.ibge.gov.br/estatisticas/multidominio/genero/20163-estatisticas-de-generoindicadores-sociais-das-mulheres-no-brasil.html? $=\& \mathrm{t}=$ resultados. Acesso em: fevereiro de 2021.

Jesus, A. M., Silveira, I. F., \& Palanch, W. B. L. (2019). Desenvolvimento do Pensamento Computacional por Meio da Colaboração: uma revisão sistemática da literatura, Revista Brasileira de Informática na Educação, 27(2), 69-90. DOI: 10.5753/rbie.2019.27.02.69 [GS $\underline{\text { Search] }}$

Kitchenham, B. (2007). Guidelines for performing Systematic Literature Reviews in Software Engineering, Technical Report. Keele University at Staffordshire and University of Durham.UK. [GS Search]

Lima, M. P. (2013). As mulheres na Ciência da Computação. Revista Estudos Feministas, 21(3), 793-816. DOI: 10.1590/S0104-026X2013000300003 [GS Search]

Martins, A., Silva, J. D., Santos, J., \& Rebouças, A. (2019). Fatores que atraem e afastam as meninas de cursos da área de TI. In: Anais do XIII Women in Information Technology (WIT 2019). XXXIX Congresso da Sociedade Brasileira de Computação (CSBC 2019). Belém: SBC. DOI: $\underline{10.5753 / \text { wit.2019.6720 [GS Search] }}$

Mattos, F., Ferreira, V., \& Anacleto, J. (2016). O Ensino de Programação com Scratch e seu Impacto na Opção Profissional para Meninas. In: Anais do SBIE 2016. DOI: $\underline{10.5753 / \text { cbie.sbie.2016.300 }}$ [GS Search] 
Moreira, J., Mattos, G., Barreto, L., Cavaco, I., \& Moreira, R. (2016). Atraindo Meninas para a Ciência da Computação: Métodos e Ferramentas. In: Anais dos Workshops do CBIE 2016. DOI: 10.5753/cbie.wcbie.2016.1255 [GS Search]

Nascimento, J. X. (2016). Políticas públicas e desigualdade de gênero na sociedade brasileira: Considerações sobre os campos do trabalho, da política e da ciência, Mediações Revista de Ciências Sociais, 21(1), p. 317-337. DOI: 10.5433/2176-6665.2016v21n1p317 [GS Search]

Nunes, D. J. (2018). Educação superior em computação - estatísticas. Recuperado de: https://www.sbc.org.br/documentos-da-sbc/send/133-estatisticas/1287-estatisticas-computacao2018. Acesso em: fevereiro de 2021.

Nunes, M. A. S. N., Louzada, C. S., Salgueiro, E. M., Andrade, B. T., Lima, P. S., \& Figueiredo, R. M. C. T. (2016a). Mapeamento de iniciativas brasileiras que fomentam a entrada de mulheres na Computação. In Anais do X Women in Information Technology, p. 56-60. Porto Alegre: SBC. DOI: $\underline{10.5753 / \text { wit.2016.9701[GS Search] }}$

Nunes, M. A. S. N., Louzada, C. S., Salgueiro, E. M., Andrade, B. T., Lima, P. S., \& Figueiredo, R. M. C. T. (2016b). Mapeamento de iniciativas estrangeiras em língua inglesa que fomentam a entrada de mulheres na Computação. In: Anais do X Women in Information Technology, p. 6165. Porto Alegre: SBC. DOI: 10.5753/wit.2016.9702 [GS Search]

Payton, F. C., \& Berki, E. (2019). Countering the negative image of women in computing. Communications of the ACM. ACM 62, 5, mai., p. 56-63. DOI: 10.1145/3319422 [GS Search]

Plataforma Nilo Peçanha. 2020. Recuperado de http://plataformanilopecanha.mec.gov.br/2020.html Acesso em: fevereiro de 2021.

Posser, C. V., \& Teixeira, A. C. (2016). Mulheres que aprendem informática: um estudo de gênero na área de TI. (2016). In: Anais do XXII Workshop de Informática na Escola (WIE 2016). V Congresso Brasileiro de Informática na Educação (CBIE 2016). Uberlândia: SBC. DOI: 10.5753/cbie.wie.2016.707 [GS Search]

Resumo Técnico do Censo da Educação Superior 2018 [recurso eletrônico]. (2020). Brasília: Instituto Nacional de Estudos e Pesquisas Educacionais Anísio Teixeira. [GS Search]

Ribeiro, K. S. F. M. (2020). Gênero, Tecnologia e Formação: o Desenvolvimento da Carreira das Estudantes do Ensino Médio Integrado em Informática, Tese (Doutorado) - Instituto de Educação, Programa de Pós-graduação em Educação, Universidade Federal de Mato Grosso, Cuiabá, 2020.

Schwartz, J., Casagrande, L. S., Leszczynski, S. A. C., \& Carvalho, M. G. (2006). Mulheres na informática: quais foram as pioneiras?, Cadernos Pagu, (27), 255-278. DOI: 10.1590/S0104$\underline{83332006000200010}$ [GS Search]

Wing, J. M. (2006). Computational thinking. Communications of ACM, 49(3), 33-35. [GS Search]

\section{Apêndice}

Apêndice - Síntese de informações dos artigos selecionados

\begin{tabular}{|c|c|c|c|}
\hline Autores & Título & Ferramentas & Instrumentos, estratégias e metodologias \\
\hline CSBC & \multicolumn{3}{|c|}{ Woman in Information Technology (WIT) } \\
\hline [1] Aires et al. (2018) & $\begin{array}{l}\text { Barreiras que Impedem a Opção das Meninas pelas Ciências Exatas e } \\
\text { Computação: Percepção de Alunas do Ensino Médio }\end{array}$ & - & $\begin{array}{l}\text { questionário, palestras e debates (projeto Meninas na } \\
\text { Computação) }\end{array}$ \\
\hline [2] Alencar et al. (2019) & $\begin{array}{c}\text { Promovendo o conhecimento sobre mulheres na Computação: experiência com } \\
\text { o jogo de cartas Computasseia no ensino de História da Computação }\end{array}$ & jogo de cartas Computasseia & $\begin{array}{c}\text { curso de extensão, questionário ( projeto Meninas } \\
\text { Digitais do Vale) }\end{array}$ \\
\hline [3] Almeida et al. (2016) & Curto-Circuito na Escola & Snap Circuits & oficina (projeto Meninas Digitais UFSC) \\
\hline [4] Amin et al. (2019) & $\begin{array}{l}\text { Oficina Gurias na Computação: três horas de imersão feminina na área da } \\
\text { Computação discutidas em detalhes }\end{array}$ & Code.org & $\begin{array}{l}\text { oficinas de Computação Desplugada, questionário } \\
\text { (projeto Gurias na Computação) }\end{array}$ \\
\hline [5] Andrade et al. (2020) & Ações Iniciais do Projeto de Extensão Garotas Tech dos Sertões de Crateús & - & questionário (Garotas Tech dos Sertões de Crateús) \\
\hline
\end{tabular}




\begin{tabular}{|c|c|c|c|}
\hline & para Captação e Retenção de Meninas aos Cursos de TI da UFC-Crateús & & \\
\hline [6] Campos e Melo (2020) & $\begin{array}{c}\text { Maria Bonita nas Ciências :: um projeto para divulgar Ciências às meninas de } \\
\text { escolas públicas }\end{array}$ & - & $\begin{array}{l}\text { minicursos, exibição de filmes, oficinas e palestras, } \\
\text { questionário (projeto Maria Bonita nas Ciências) }\end{array}$ \\
\hline [7] Cardoso et al. (2016) & Empoderamento Feminino com Dispositivos Móveis & App Inventor & questionário, oficina (projeto Meninas Digitais UFSC) \\
\hline [8] Coelho et al. (2016) & Incentivando o Ingresso de Mulheres nos Cursos de Engenharia e Tecnologia & Kit de eletrônica LittleBits & questionário, oficina (projeto Meninas Digitais UFSC) \\
\hline [9] Cruz et al. (2020) & $\begin{array}{l}\text { Criação de representações usando e-lixo para homenagear mulheres da } \\
\text { Computação }\end{array}$ & Lixo eletrônico & oficinas (projeto Emíli@s - Armação em bits) \\
\hline [10] Deus et al (2020) & $\begin{array}{l}\text { Um Estudo sobre as Dificuldades de Inserção de Meninas na } \\
\text { Computação }\end{array}$ & - & questionário \\
\hline [11] Ferrão e Melo (2016) & I Fórum Gurias na Computação: relato de experiências e desdobramentos & - & fórum (projeto Gurias na Computação) \\
\hline [12] Ferreira e Dias (2019) & $\begin{array}{l}\text { A influência de uma ação de inclusão no interesse das alunas de ensino médio } \\
\text { em cursar Computação na Universidade Federal de Goiás }\end{array}$ & - & evento (salas temáticas), questionário (Projeto ADAs) \\
\hline $\begin{array}{l}\text { [13] Figueiredo e Maciel } \\
\qquad(2016)\end{array}$ & Reflexões sobre gêneros, tecnologia e processo vocacional & - & $\begin{array}{l}\text { análise teórica sobre relações de gênero, tecnologia e } \\
\text { processo vocacional }\end{array}$ \\
\hline $\begin{array}{l}\text { [14] Figueiredo et al. } \\
\text { (2016) }\end{array}$ & $\begin{array}{l}\text { Meninas Digitais Regional Mato Grosso: Práticas Motivacionais no Ensino } \\
\text { Médio para a Equidade de Gêneros nas Carreiras e Cursos de Computação e } \\
\text { Tecnologias }\end{array}$ & $\begin{array}{l}\text { App Inventor, Construct } 2 \\
\text { HTML/CSS }\end{array}$ & $\begin{array}{l}\text { (oficinas, produção de material informativo, } \\
\text { participação e organização de eventos) projeto Meninas } \\
\text { Digitais Regional Mato Grosso }\end{array}$ \\
\hline $\begin{array}{l}\text { [15] Figueiredo et al. } \\
\text { (2017) }\end{array}$ & Percepções de alunas de Ensino Médio sobre as subáreas da Computação & - & $\begin{array}{c}\text { questionário (projeto Meninas Digitais Regional Mato } \\
\text { Grosso) }\end{array}$ \\
\hline [16] Fiori et al. (2019) & $\begin{array}{l}\text { Uma experiência de aprendizagem de lógica de programação com Code.org no } \\
\text { ensino médio: uma análise por gênero sobre a percepção dos estudantes }\end{array}$ & Code.org & oficina, questionário (projeto Meninas Digitais do Vale) \\
\hline [17] Gimenez et al. (2016) & Meninas, Computação e Música & $\begin{array}{l}\text { instrumentos musicais, } \\
\text { teclado, Java, Greenfoot }\end{array}$ & aulas (projeto Meninas, Computação e Música) \\
\hline [18] Grings et al.(2018) & Meninas do Ensino Médio: Quem quer estudar TI? & - & questionário \\
\hline $\begin{array}{l}\text { [19] Holanda, Mourão, et } \\
\text { al. (2017) }\end{array}$ & $\begin{array}{l}\text { Uma Pesquisa com Alunas do Ensino Fundamental e Médio sobre os Cursos } \\
\text { da Área de Computação }\end{array}$ & - & questionário (projeto Meninas.comp) \\
\hline [20] Holanda et al. (2016) & $\begin{array}{c}\text { Meninas.comp: Um Relato da Experiência de Integração entre o Ensino Médio } \\
\text { e a Universidade de Brasília }\end{array}$ & $\begin{array}{c}\text { Kit LEGO, robôs sparks, } \\
\text { placas de Arduino, sensores, } \\
\text { notebooks }\end{array}$ & $\begin{array}{l}\text { aulas, visitas ao laboratório, apresentação em eventos } \\
\text { (projeto Meninas.comp) }\end{array}$ \\
\hline [21] Lima et al. (2020) & $\begin{array}{c}\text { Utilizando Oficinas Educacionais de Empoderamento Feminino para Inclusão } \\
\text { Digital e Social de Estudantes do Ensino Médio }\end{array}$ & PIC-PAC stop motion & $\begin{array}{l}\text { oficinas, palestras, questionário (projeto Meninas } \\
\text { Paid'éguas) }\end{array}$ \\
\hline [22] Manentti et al. (2016) & Robótica na aprendizagem de física e matemática para alunas do ensino médio & Kit LEGO & curso \\
\hline [23] Mattos et al. (2020) & $\begin{array}{l}\text { Despertando Vocações Através da Capacitação em Tecnologia: Experiências } \\
\text { com Alunas do Ensino Médio da ECI EEFM Professor Celestin Malzac }\end{array}$ & App Inventor & $\begin{array}{c}\text { minicurso, palestras, debates, questionário, Computação } \\
\text { Desplugada }\end{array}$ \\
\hline [24] Moura et al. (2018) & $\begin{array}{l}\text { Incentivando alunas do Ensino Médio a Ingressarem em Carreiras de Ciência e } \\
\text { Tecnologia na Paraíba }\end{array}$ & $\begin{array}{l}\text { Scratch, LightBot e MIT } \\
\quad \text { App Inventor }\end{array}$ & oficinas, palestras, visitas (projeto de extensão) \\
\hline [25]Nakamura et al. (2017) & Hora do Vestibular: o que as estudantes do ensino médio almejam fazer? & - & questionário (projeto Cunhantã Digital) \\
\hline $\begin{array}{l}\text { [26] Ribeiro e Maciel } \\
\text { (2020a) }\end{array}$ & $\begin{array}{l}\text { Fatores de Influência na Escolha pela Continuidade da Carreira em } \\
\text { Computação pelas Estudantes de Ensino Médio Técnico em Informática }\end{array}$ & - & questionário (projeto Meninas Digitais Mato Grosso) \\
\hline [27] Ribeiro et al. (2016) & Trazendo Meninas para a Computação & $\begin{array}{l}\text { Scratch, HTML, kit LEGO, } \\
\text { MovieMaker }\end{array}$ & $\begin{array}{l}\text { oficinas, visitas (projeto Trazendo Meninas para a } \\
\text { Computação) }\end{array}$ \\
\hline [28] Ridel et al. (2018) & $\begin{array}{l}\text { Technovation Hackday @ ICMC-USP Um instrumento de difusão e } \\
\text { articulação de meninas na computação }\end{array}$ & App Inventor & palestras, oficina \\
\hline [29] Santana et al. (2017) & $\begin{array}{l}\text { A importância de atividades de empoderamento feminino como forma de } \\
\text { minimizar a evasão das mulheres nos cursos de Tecnologia da Informação }\end{array}$ & - & $\begin{array}{l}\text { debates, mesas redondas, palestras, filmes, painéis, } \\
\text { murais, oficinas, visitas técnicas, coletivo de estudos }\end{array}$ \\
\hline $\begin{array}{l}\text { [30] Santos e Oliveira } \\
\text { Filho }(2020)\end{array}$ & $\begin{array}{l}\text { Robótica e Interdisciplinaridade: Aprendizagem Criativa Atraindo Meninas } \\
\text { para a Tecnologia }\end{array}$ & Scratch, S4A; IDE Arduino & aulas (projeto Metabotix) \\
\hline [31] Santos et al. (2016) & $\begin{array}{l}\text { Incentivando meninas do ensino médio a ingressarem nas áreas tecnológicas } \\
\text { com curso de programação e robótica }\end{array}$ & Kit LEGO, VisualG & $\begin{array}{l}\text { questionário, aulas (parte de um projeto de } \\
\text { universidade) }\end{array}$ \\
\hline $\begin{array}{l}\text { [32] Santos, Santos, et al. } \\
\text { (2017) }\end{array}$ & A Computação sob a Ótica de Meninas do Ensino Médio & - & questionário \\
\hline $\begin{array}{l}\text { [33] Santos, Silva, et al. } \\
\text { (2017) }\end{array}$ & $\begin{array}{c}\text { Explorando o Pensamento Computacional para Despertar Novos Talentos: } \\
\text { Relato de uma Experiência }\end{array}$ & App Inventor & palestra, curso (projeto Meninas Digitais Tchê Missões) \\
\hline $\begin{array}{l}\text { [34] Sardinã e Maciel } \\
\qquad(2016)\end{array}$ & $\begin{array}{l}\text { Ações para Incentivar Meninas do Ensino Médio a Cursar Carreiras } \\
\text { Tecnológicas da Universidade Federal do Rio Grande do Norte }\end{array}$ & HTML & $\begin{array}{l}\text { cursos (Web, Banco de dados, HTML, Android, Redes } \\
\text { etc.) atividades de extensão entre universidade e escolas } \\
\text { públicas (programa Meninas Digitais) }\end{array}$ \\
\hline [35] Sidnei et al. (2020) & $\begin{array}{l}\text { Por que as mulheres são minoria nos cursos de computação? Um estudo desta } \\
\text { situação na cidade de Ouro Branco-MG }\end{array}$ & - & questionário \\
\hline $\begin{array}{l}\text { [36] Silva Neto e } \\
\text { Casagranda (2017) }\end{array}$ & $\begin{array}{c}\text { Relatos de Experiências da participação de Mato Grosso no Technovation } \\
\text { Challenge } 2017\end{array}$ & - & $\begin{array}{c}\text { competição (projeto Meninas Digitais Regional Mato } \\
\text { Grosso) }\end{array}$ \\
\hline [37] Silva et al. (2020) & $\begin{array}{l}\text { Competições de programação para meninas do ensino médio: Afinal, era } \\
\text { apenas uma questão de propósito! }\end{array}$ & - & $\begin{array}{l}\text { análise sobre competições } \\
\text { (programa MinasCoders) }\end{array}$ \\
\hline [38] Soares et al. (2018) & $\begin{array}{c}\text { Mulheres de Ferro: Relato de Prática Utilizando Arduíno com Alunas do } \\
\text { Ensino Médio em uma Escola Pública }\end{array}$ & Kits de Arduíno & oficina, questionário \\
\hline [39] Sousa et al. (2019) & $\begin{array}{l}\text { Perfis das estudantes dos cursos de Informática do Instituto Federal de } \\
\text { Educação, Ciência e Tecnologia de São Paulo (IFSP), campus Bragança }\end{array}$ & - & $\begin{array}{l}\text { questionário ( projeto de extensão } \operatorname{IF}(\text { meninas) } \text { \{nas } \\
\text { exatas }\} \text { ) }\end{array}$ \\
\hline
\end{tabular}




\begin{tabular}{|c|c|c|c|}
\hline & Paulista & & \\
\hline CSBC & \multicolumn{3}{|c|}{ Workshop sobre Educação em Computação (WEI) } \\
\hline [40] Bim (2011) & $\begin{array}{c}\text { Uma experiência de ensino de Interação Humano-Computador para alunas do } \\
\text { ensino médio }\end{array}$ & - & minicurso \\
\hline [41] Mattos et al. (2018) & $\begin{array}{c}\text { Oficinas de Programação para Meninas: Despertando o Interesse Pela } \\
\text { Computação }\end{array}$ & $\begin{array}{l}\text { Lightbot, Code.org, Scratch, } \\
\text { App Inventor }\end{array}$ & questionário, oficinas, palestras (projeto de extensão) \\
\hline [42] Mattos et al. (2015) & $\begin{array}{l}\text { A Utilização de Kits de Robótica como Ferramenta para o Ensino de } \\
\text { Programação à Meninas do Ensino Médio }\end{array}$ & Kit ROBO TX Explorer & $\begin{array}{l}\text { oficinas, questionário, rodas de conversa (projeto } \\
\text { Mulheres na Ciência da Computação) }\end{array}$ \\
\hline [43] Pinto et al. (2020) & $\begin{array}{l}\text { Quando a Aluna se Torna a Mestre: Um Relato da Experiência de Alunas de } \\
\text { Graduação Aplicando Dinâmicas de Ensino de Computação para Alunas de } \\
\text { Ensino Médio }\end{array}$ & Scratch & $\begin{array}{l}\text { gincana, questionário, Computação desplugada (projeto } \\
\text { PETComp) }\end{array}$ \\
\hline [44] Ramos et al. (2015) & $\begin{array}{c}\text { Ensino de Programação para Alunas de Ensino Médio: Relato de uma } \\
\text { Experiência }\end{array}$ & App Inventor & $\begin{array}{l}\text { palestra, curso, questionário (projeto Android Smart } \\
\text { Girls) }\end{array}$ \\
\hline CBIE & \multicolumn{3}{|c|}{ Workshop de Informática na Escola (WIE) } \\
\hline [45] Berardi et al. (2019) & $\begin{array}{l}\text { Oficina de Banco de Dados com Aprendizado Cinestésico para Meninas do } \\
\text { Ensino Médio }\end{array}$ & Kahoot & oficina, questionário, Computação desplugada \\
\hline [46] Gomes et al. (2014) & $\begin{array}{l}\text { Incentivando meninas do ensino médio à área de Ciência } \\
\text { da Computação usando o Scratch como ferramenta }\end{array}$ & Scratch & questionário, curso \\
\hline [47] Matos et al. (2019) & $\begin{array}{l}\text { Desenvolvimento de Jogos para Incentivar Meninas na Área da Tecnologia de } \\
\text { Informação: um estudo de caso no ensino médio de escola pública }\end{array}$ & Construct 2, VisualG & palestra, aulas. questionário \\
\hline [48] Nunes et al. (2015) & $\begin{array}{l}\text { Uma iniciativa para atrair as estudantes do ensino médio } \\
\text { para a Área de Tecnologia da Informação }\end{array}$ & HTML, CSS & palestras, dinâmicas, minicursos, questionário \\
\hline [49] Santos et al. (2019) & $\begin{array}{l}\text { Tecendo Espaços e Experiências no Campo da Robótica Educacional para } \\
\text { Fomentar o Interesse de Meninas pela área de Computação }\end{array}$ & $\begin{array}{l}\text { Kit robótico Robô Sumô } \\
\text { Arduino UR20, }\end{array}$ & oficinas \\
\hline $\begin{array}{l}\text { [50] Santos, Silva, } \\
\text { Silveira, et al. (2017) }\end{array}$ & $\begin{array}{c}\text { Desafio de Programação para Meninas do Ensino Médio: Um Relato de } \\
\text { Experiência }\end{array}$ & App Inventor & $\begin{array}{c}\text { palestras, oficinas, cursos, ateliers, competição (projeto } \\
\text { Desafio de Programação) }\end{array}$ \\
\hline CBIE & \multicolumn{3}{|c|}{ Anais dos Workshops do CBIE } \\
\hline [51] Frigo et al. (2013) & $\begin{array}{c}\text { Tecnologias Computacionais como Práticas Motivacionais } \\
\text { no Ensino Médio }\end{array}$ & $\begin{array}{c}\text { HTML, LEGO Mindstorms, } \\
\text { kit de robótica }\end{array}$ & oficinas, questionário (projeto de extensão) \\
\hline [52] Pontes et al. (2019) & Desafios no incentivo de meninas para a área de Computação & - & $\begin{array}{l}\text { visita, palestras, mostra de filmes, oficinas de } \\
\text { Computação desplugada }\end{array}$ \\
\hline $\begin{array}{l}\text { [53] Ribeiro e Maciel } \\
(2020 \mathrm{~b})\end{array}$ & $\begin{array}{l}\text { Um Estudo sobre o Desenvolvimento da Carreira das } \\
\text { Estudantes do Ensino Médio Integrado em Informática }\end{array}$ & - & $\begin{array}{l}\text { entrevistas, questionários, grupos focais (projeto de } \\
\text { extensão) }\end{array}$ \\
\hline \multicolumn{4}{|c|}{ Google Scholar } \\
\hline [54] Brito et al. (2015) & $\begin{array}{l}\text { Meninas na Ciência: atraindo jovens mulheres } \\
\text { para carreiras de Ciência e Tecnologia }\end{array}$ & - & $\begin{array}{l}\text { visitas, debates, filmes, oficinas, feira, produção de } \\
\text { vídeos, questionário (projeto Meninas na Ciência) }\end{array}$ \\
\hline $\begin{array}{l}\text { [55] Holanda, Walter, et al. } \\
\text { (2017) }\end{array}$ & $\begin{array}{c}\text { Meninas.comp: } \\
\text { Computação também é coisa de menina }\end{array}$ & $\begin{array}{l}\text { Kodu, kits de Eletrônica } \\
\text { Educacional, LEGO }\end{array}$ & $\begin{array}{l}\text { oficinas, fóruns, feiras, questionários (projeto } \\
\text { Meninas.comp) }\end{array}$ \\
\hline [56] Petró et al. (2020) & $\begin{array}{c}\text { "Meninas também sabem programar": relato de experiência de um projeto } \\
\text { sobre gênero e informática no ensino médio }\end{array}$ & - & $\begin{array}{l}\text { aulas, entrevistas, produção material audiovisual } \\
\text { (vídeo), exposição }\end{array}$ \\
\hline \multicolumn{4}{|c|}{ IEEE Xplore } \\
\hline $\begin{array}{l}\text { [57] Holanda, Mourao, et } \\
\text { al. (2020) }\end{array}$ & $\begin{array}{l}\text { What do Female Students in Middle and High } \\
\text { Schools Think about Computer Science Majors in } \\
\text { Brasilia, Brazil? A Survey in } 2011 \text { and } 2019\end{array}$ & - & questionário \\
\hline $\begin{array}{l}\text { [58] Holanda, Araujo, et } \\
\text { al. (2020) }\end{array}$ & $\begin{array}{c}\text { Meninas.comp Project: Programming for Girls in } \\
\text { High School in Brazil }\end{array}$ & $\begin{array}{l}\text { Kodu, kits de eletrônica, } \\
\text { LEGO, App Inventor }\end{array}$ & oficinas (projeto Meninas.comp) \\
\hline [59] Maciel et al. (2018) & $\begin{array}{l}\text { Digital Girls Program - Disseminating Computer Science to Girls } \\
\text { in Brazil }\end{array}$ & - & Programa Meninas Digitais da SBC \\
\hline $\begin{array}{l}\text { [60] Mota e Adamatti } \\
\text { (2015) }\end{array}$ & $\begin{array}{c}\text { Programming Teaching in High Schools: an analysis } \\
\text { based on the Discourse of Collective Subject }\end{array}$ & Scratch & oficinas, questionário \\
\hline [61] Moreira et al. (2019) & $\begin{array}{c}\text { Robotics Teaching and Tools to Promote Better } \\
\text { Didactic in Public High-Schools }\end{array}$ & $\begin{array}{c}\text { Kit Sparki, by ArcBotics, } \\
\text { C }++\end{array}$ & oficinas, questionário, entrevistas, observações \\
\hline [62] Sauer et al. (2020) & $\begin{array}{l}\text { Work-in-Progress: Encouraging Girls in Science, } \\
\text { Engineering and Information Technology }\end{array}$ & - & $\begin{array}{l}\text { cursos, oficinas, feiras de ciência e tecnologia, } \\
\text { olimpíadas, fóruns (Projeto Encorajando meninas em } \\
\text { Ciência, Engenharia e Tecnologia da Informação) }\end{array}$ \\
\hline [63] Sousa et al. (2020) & $\begin{array}{c}\text { Robotics as a Tool for Deconstructing Stereotypes in Amazon: } \\
\text { Disseminating Information in Baixo Trombetas }\end{array}$ & $\begin{array}{l}\text { Scratch, Python, } \mathrm{C}++, \\
\text { Arduino }\end{array}$ & $\begin{array}{c}\text { cursos, competições, eventos, oficinas (projeto } \\
\text { Cunhantã Digital) }\end{array}$ \\
\hline
\end{tabular}

